\title{
Article \\ Adjective Placement in English/Spanish Mixed Determiner Phrases: Insights from Acceptability Judgments
}

\author{
Irati De Nicolás ${ }^{1, *}$ and Luis López ${ }^{2}$ \\ 1 Department of Romance Languages and Literatures, University of Chicago, Chicago, IL 60637, USA \\ 2 Department of Hispanic and Italian Studies, University of Illinois at Chicago, Chicago, IL 60607, USA; \\ luislope@uic.edu \\ * Correspondence: idenicolassaiz@uchicago.edu
}

check for updates

Citation: De Nicolás, Irati, and Luis López. 2022. Adjective Placement in English/Spanish Mixed Determiner Phrases: Insights from Acceptability Judgments. Languages 7: 54. https:// doi.org/10.3390/languages7010054

Academic Editor: Bryan

Koronkiewicz

Received: 1 August 2021

Accepted: 25 January 2022

Published: 28 February 2022

Publisher's Note: MDPI stays neutral with regard to jurisdictional claims in published maps and institutional affiliations.

Copyright: (C) 2022 by the authors. Licensee MDPI, Basel, Switzerland. This article is an open access article distributed under the terms and conditions of the Creative Commons Attribution (CC BY) license (https:// creativecommons.org/licenses/by/ $4.0 /)$.

\begin{abstract}
The present study examines the relative order of noun-adjective sequences within codeswitched Determiner Phrases. Several hypotheses have been considered: (i) Order is a property defined by the noun; (ii) it is a property defined by the adjective; (iii) it is a property governed by the carrier phrase. The studies that have investigated the issue all assume that the class of adjectives is homogeneous, but in fact, there exist several sub-classes of adjectives which in many languages, including Spanish, exhibit distinct ordering properties. We propose to add the variable 'adjective type to our study and use code-switching of English/Spanish, two languages that differ in the position of adjectives, as our database. A total of thirty English/Spanish heritage speakers took part in an experiment. Our results show that both the language of the adjective and the carrier phrase are significant factors of word order in the noun phrase; on the other hand, the noun itself does not seem to play a role.
\end{abstract}

Keywords: code-switching; bilingualism; heritage speakers; word order

\section{Introduction}

Adjective placement has attracted the attention of many authors (Arnaus Gil et al. 2012; Cantone and MacSwan 2009; Parafita Couto et al. 2015, 2017) and many studies have analyzed which element determines the adjective-noun order within the Determiner Phrase (DP). Results of the code-switching studies vary: Arnaus Gil et al. (2012) argue that the noun determines word order within the DP, Cantone and MacSwan (2009) and Moro Quintanilla (2016) found that the adjective does while there is a rich line of research that argues that the matrix language (ML) (in Myers-Scotton framework)/the carrier phrase has an effect on the noun-adjective order (Parafita Couto et al. 2015, 2017).

The topic of this article goes to the heart of a crucial topic in grammatical theory: the role of grammatical features in setting up syntactic dependencies. Assume, for the sake of argument, a Cinque-style understanding of DP structure (Cinque 2005, 2010): the order leftto-right reflects c-command (as in Kayne 1993) and, in the base structure, adjectives precede and c-command the head noun. Any linearization of the noun to the left of the adjective must be the outcome of movement of the noun to a higher c-commanding position. Finally, let us also assume that the mechanisms of Concord express a grammatical relationship between a functional category that we may call $a$ (belonging to the extended projection of the adjective) and another functional category which, following a long tradition, we may call $n$, the noun (see Marantz 1997 and much subsequent work). This grammatical relationship results in copying gender and number features from the noun onto $a$, as in the Agree operation postulated in Chomsky (2000).

With these assumptions, we can consider two scenarios. In scenario 1, we find that the relative order of noun and adjective within the DP depends on the language of the adjective. In our little theory sketched above, this would entail that $a$ would have the capacity of triggering displacement of the noun to the left of the adjective-a mechanism that would 
look very much like the displacement mechanism proposed in Chomsky (2000). In scenario 2 , the order depends on the language of the noun. If this is the case, noun movement is motivated by a feature in the noun itself, as in the framework of assumptions presented in Chomsky (1993). Thus, the study of word order in code-switched DPs provides data that can illuminate a central theoretical issue.

The debate rages on because counterexamples to all the theories have been attested in the literature. For example, in (1), we have an example with a Spanish noun and a German adjective with the NA order. In (2), we have a German noun with an Italian adjective appearing post-nominally. If the adjective dictated the order of the constituents within the DP (Cantone and MacSwan 2009), (1) should be ungrammatical because German adjectives appear pre-nominally, and therefore, the adjective should appear pre-nominally. However, this example appears in Arnaus Gil et al.'s (2012) corpus. On the other hand, Arnaus Gil et al. (2012) argue that the noun dictates the order of constituents within the DP. If that is the case, the example in (2) should be ungrammatical because German nouns must have adjectives to their left; however, this switch was judged acceptable by the participants in Cantone and MacSwan's study.

(1)

Una cosa schwerer

A thing heavier

'A heavier thing'

(2)

$$
\begin{aligned}
& \text { Una Gegend fredda } \\
& \text { one region cold } \\
& \text { 'one cold region' }
\end{aligned}
$$

(German-Spanish)

(Arnaus Gil et al. 2012, p. 19)

(Italian-German)

(Cantone and MacSwan 2009, p. 263)

These studies take adjectives to be a homogeneous group. However, we know that adjectives belong to different categories with grammatical properties that are overtly distinct in many languages (Cinque 2010; Taboada 2010). One of these languages is Spanish: some adjectives in this language are post-verbal, others are pre-verbal, and yet others can appear in post- or pre-verbal position. Bartlett (2013) and Taboada (2010) use this empirical fact to propose a division of adjectives by type in Spanish that impacts the relative constituent order of the adjective and the noun. To introduce a random example, Spanish qualifying adjectives can appear pre-nominally or post-nominally. An example of this type of adjectives is simpático 'nice' that can appear pre-nominally or post-nominally with no change in meaning, as observed in (3).

$$
\begin{aligned}
& \text { a. El fontanero simpático } \\
& \text { The plumber nice } \\
& \text { 'the nice plumber' } \\
& \text { b. El simpático fontanero } \\
& \text { the nice plumber } \\
& \text { 'the nice plumber' }
\end{aligned}
$$

The division proposed by Bartlett (2013) and Taboada (2010) takes into account the different adjective positions in relation to the noun. It follows that different types of adjectives yield different predictions in code-switching situations; thus, this division is crucial because it has a direct effect on the interpretation of the results. For example, in their study, Stadthagen-González et al. (2017) used adjectives such as caliente 'hot'. Although the unmarked position for this adjective is post-nominal, it can be used prenominally in Spanish (La caliente discusión entre los concursantes 'the heated argument among participants'). According to the authors, the Adjective Theory predicts a sentence such as 'Necesito un caliente bath' ('I need a hot bath') to be ungrammatical. However, as these adjectives can appear pre-nominally in Spanish, it can be the case that participants accept these adjectives pre-nominally. Thus, it is important to select exclusively post-nominal adjectives or, on the contrary, predictions should be made accordingly. 
The aim of this paper is to test if the noun (Arnaus Gil et al. 2012), the adjective (Cantone and MacSwan 2009), or the Matrix Language (ML) (Parafita Couto et al. 2015, 2017) determines the order of the DP by conducting a Spanish/English code-switching experiment. These language pairs are selected because they differ in the position of adjectives: English adjectives are prenominal in the general case (the new house) while Spanish adjectives vary. In addition, in this experiment, we look into the noun-adjective problem taking into account the division of Spanish adjectives by types.

The analysis of the results of the CS experiments provide evidence that the adjective determines the order of the DP although some results require further discussion. These findings align with previous CS accounts (Cantone and MacSwan 2009; Moro Quintanilla 2016; Stadthagen-González et al. 2017).

This paper is organized as follows: in the next section, we provide a review of adjective placement in Spanish and English. In Section 3, we present some of the most important studies that have reviewed adjective-noun order in code switching. Section 4 discusses the methodology used for our experiment. Sections 5 and 6 present the results and the discussion of our experiment and finally, Section 7 concludes this paper.

\section{Adjective Placement in Spanish and English}

\subsection{Adjective Placement in Spanish}

Traditionally, it has been established that there are three main classes of adjectives in Spanish (Demonte 1999): (1) Adverbial adjectives, (2) qualifying adjectives and (3) relational adjectives. Bartlett (2013) and Taboada (2010), on the other hand, propose another distinction and classify Spanish adjectives in four types on the basis of their position within the DP.

The first type of adjectives (also referred to as Type 1), also known as adverbial adjectives, contains adjectives that are only pre-nominal such as mero 'mere' and supuesto 'alleged':

(4)

$$
\begin{aligned}
& \text { El supuesto criminal } \\
& \text { The alleged criminal } \\
& \text { 'The alleged criminal' } \\
& \text { *El criminal supuesto } \\
& \text { The criminal alleged } \\
& \text { 'The alleged criminal' }
\end{aligned}
$$

(DAN order)

(DNA order)

\section{(De Nicolas and Robledo 2018, p. 65)}

The second broad class of adjectives is qualifying adjectives. Bartlett and Taboada divide qualifying adjectives in two different types, what they call Type 2 and Type 3 adjectives:

Type 2 adjectives are called 'PRE/POS change' adjectives by Bartlett (2013). They are so called because the denotation of the noun phrase changes depending on the position in which the adjective appears. An example of this type of adjective is viejo 'old'. Consider examples (6) and (7). In example (6), viejo 'old' appears post-nominally and the denotation of the noun phrase is a friend that has reached an advanced age. When viejo appears pre-nominally (7), the denotation is that of a friend you have known for many years.

(6)

$$
\begin{aligned}
& \text { Un amigo viejo } \\
& \text { A friend old } \\
& \text { 'An old friend' } \\
& \text { Un viejo amigo } \\
& \text { An old friend } \\
& \text { 'An old friend' }
\end{aligned}
$$

(A friend who is many years old)

(A friend you have known for many years) (De Nicolas and Robledo 2018, p. 65)

The third type (Type 3) refers to adjectives that can appear pre-nominally or postnominally but the denotation of the referent does not change. Bartlett calls these adjectives 'PRE/POS no change'. An example of this type of adjective is timido 'timid'. In examples (8) 
and (9), the denotation of the noun phrase is the same in both instances: a timid man. This contrasts with the examples above (6-7).

(8) Un hombre tímido

A man timid

'A timid man'

(9) Un tímido hombre

A timid man

'A timid man'

(De Nicolas and Robledo 2018, p. 65)

It has been argued that the unmarked position for Type 3 adjectives is postnominal (Bosque 2001).

Finally, Bartlett (2012) and Taboada (2010) distinguish a last type of adjectives: Type 4 adjectives. These adjectives have been called relational adjectives in the Romance and English literature (Bortolotto 2016; Brinker 1974; Bosque 1993; Boleda and McNally 2004; Fábregas 2007, among others). Type 4 adjectives can only appear post-nominally (10a) (Bally 1965):
(10) a. La red eléctrica The net electric
'The electric net'
b. *La eléctrica red
The electric net
'The electric net'

(De Nicolas and Robledo 2018, p. 65)

Cinque $(2005,2010)$ argues that the same division of Spanish adjectives also holds for the other Romance languages.

\subsection{Adjective Placement in English}

In English, adjectives are always prenominal as illustrated in the following examples (11-14) ${ }^{1}$. In general, adverbial (Type 1), qualifying (Type 2 and Type 3), and relational (Type 4) adjectives appear before the noun in English. In the following Table 1, we have included the division of adjectives discussed in the previous section for Spanish with English adjectives. As observed, they always precede the noun.

Table 1. Summary of adjective types in Spanish and in English.

\begin{tabular}{|c|c|c|c|c|c|c|c|c|c|c|c|c|c|c|c|c|c|c|c|c|}
\hline \multirow[b]{3}{*}{ En. } & \multirow{2}{*}{\multicolumn{5}{|c|}{$\begin{array}{c}\text { Adverbial Adjectives } \\
\text { Type } 1\end{array}$}} & \multicolumn{10}{|c|}{ Qualifying Adjectives } & \multirow{2}{*}{\multicolumn{5}{|c|}{$\begin{array}{c}\text { Relational Adjectives } \\
\text { Type } 4\end{array}$}} \\
\hline & & & & & & \multicolumn{5}{|c|}{ Type 2} & \multicolumn{5}{|c|}{ Type 3} & & & & & \\
\hline & (11) & $\begin{array}{l}\text { a. } \\
\text { b. }\end{array}$ & $\begin{array}{l}\text { An } \\
{ }^{*} \mathrm{~A}\end{array}$ & $\begin{array}{l}\text { alleged } \\
\text { criminal }\end{array}$ & $\begin{array}{l}\text { criminal } \\
\text { alleged }\end{array}$ & (12) & $\begin{array}{l}\text { a. } \\
\text { b. }\end{array}$ & $\begin{array}{l}\text { An } \\
{ }^{*} \mathrm{~A}\end{array}$ & $\begin{array}{l}\text { old } \\
\text { friend }\end{array}$ & $\begin{array}{l}\text { friend } \\
\text { old }\end{array}$ & (13) & $\begin{array}{l}\text { a. } \\
\text { b. }\end{array}$ & $\begin{array}{l}\mathrm{A} \\
{ }^{*} \mathrm{~A}\end{array}$ & $\begin{array}{l}\text { timid } \\
\text { man }\end{array}$ & $\begin{array}{l}\text { man } \\
\text { timid }\end{array}$ & (14) & $\begin{array}{l}\text { a. } \\
\text { b. }\end{array}$ & $\begin{array}{l}\text { An } \\
{ }^{*} \mathrm{~A}\end{array}$ & $\begin{array}{l}\text { electric } \\
\text { net }\end{array}$ & $\begin{array}{l}\text { net } \\
\text { electric }\end{array}$ \\
\hline Sp. & (15) & $\begin{array}{l}\text { a. } \\
\text { b. }\end{array}$ & $\begin{array}{l}\text { Un } \\
{ }^{*} \text { Un } \\
\text { 'An }\end{array}$ & $\begin{array}{l}\text { supuesto } \\
\text { criminal } \\
\text { alleged }\end{array}$ & $\begin{array}{l}\text { criminal } \\
\text { supuesto } \\
\text { criminal' }\end{array}$ & (16) & $\begin{array}{l}\text { a. } \\
\text { b. }\end{array}$ & $\begin{array}{l}\text { Un } \\
\text { Un } \\
\text { 'An }\end{array}$ & $\begin{array}{l}\text { viejo } \\
\text { amigo } \\
\text { old }\end{array}$ & $\begin{array}{l}\text { amigo } \\
\text { viejo } \\
\text { friend' }\end{array}$ & (17) & $\begin{array}{l}\text { a. } \\
\text { b. }\end{array}$ & $\begin{array}{l}\text { Un } \\
\text { Un } \\
\text { 'A }\end{array}$ & $\begin{array}{l}\text { hombre } \\
\text { tímido } \\
\text { nice }\end{array}$ & $\begin{array}{l}\text { tímido } \\
\text { hombre } \\
\text { man' }\end{array}$ & (18) & $\begin{array}{l}\text { a. } \\
\text { b. }\end{array}$ & $\begin{array}{l}\text { Una } \\
{ }^{*} \text { Una } \\
\text { ‘An }\end{array}$ & $\begin{array}{l}\text { red } \\
\text { eléctrica } \\
\text { electric }\end{array}$ & $\begin{array}{l}\text { eléctrica } \\
\text { red } \\
\text { net' }^{\prime}\end{array}$ \\
\hline
\end{tabular}

For Type 2 qualifying adjectives in English (12), the semantic change present in Spanish is also present in English and (12) may carry both meanings (a friend who is many years old and a friend you have known for many years). In English, this difference is obtained from the context, unlike in Spanish (recall that this difference depends on the position of the adjective).

Some authors (Cinque 2010; Camacho 2018) argue that the unmarked position for English adjectives is prenominal and thus, it can be said that Spanish and English diverge in the position of the adjective.

For this paper, we will adopt Bartlett's terminology and we will name pre-nominal Spanish adjectives Type 1 adjectives, qualifying "PRE/POS change in meaning" adjectives Type 2; qualifying "PRE/POS no change" Type 3 adjectives; and only postnominal adjec- 
tives Type 4 adjectives (relational adjectives). We will also use this terminology to refer to their English equivalents.

\section{Background}

Several studies have analyzed the NA or AN order within the DP using code switching data. Most of the studies have investigated the different adjective-noun orderings among languages with different adjective placement. These studies have come up with different results: some of them found that that the $\mathrm{N}$ determines word order within the DP (N theory), while some others have argued that the A determines it (A theory). In addition, there is a rich line of research that has claimed that the language of the carrier phrase can have an effect in determining the respective order of noun and adjective.

A few studies claimed that the determiner (D) determines the noun-adjective order (D theory) (Bartlett 2012; Di Sciullo 2014). However, Bartlett's experiment was only tested with one German/Spanish bilingual and Di Sciullo (2014) did not experimentally test her theory. Hence, we do not really have an articulated, empirically based, analysis of adjective-noun order based on the determiner. In addition, there is some empirical work that explicitly addresses this question, and the result is negative: in a recent study of Basque/Spanish code-switched DPs, De Nicolas and Robledo (2018) found that the determiner does not influence the order of the adjective and noun. We therefore conclude that it is very unlikely that D will play any role in the NA order and thus, for the purposes of this paper, we leave aside the D hypothesis, and we focus our attention on the noun, the adjective, and the matrix language hypotheses. This section provides a review of these studies and their findings.

The studies we present assume the following:

(1) One universal DP structure for Germanic and Romance languages and one underlying common structure for prenominal and postnominal adjectives (Cinque 1994, 2005, 2010). The underlying structure proposed is $\mathrm{A}>\mathrm{N}$.

(2) Noun movement happens in Romance and that is how the post-nominal adjective position is obtained (Longobardi 1994; Cinque 2010). Noun movement, however, must be relatively short, because in these languages, Type 3 adjectives may appear to the left or the right of the noun. This would seem to indicate that nouns may move to a position from which they c-command Type 3 adjectives or to a lower position in which Type 3 adjectives c-command the noun.

(3) In Germanic languages, on the other hand, noun movement does not happen with the resulting order of AN. In (19), we illustrate these ideas by using Cantone and MacSwans' tree structure, which includes an Agreement Phrase that attracts the noun to its spec position, leaving the adjective behind.

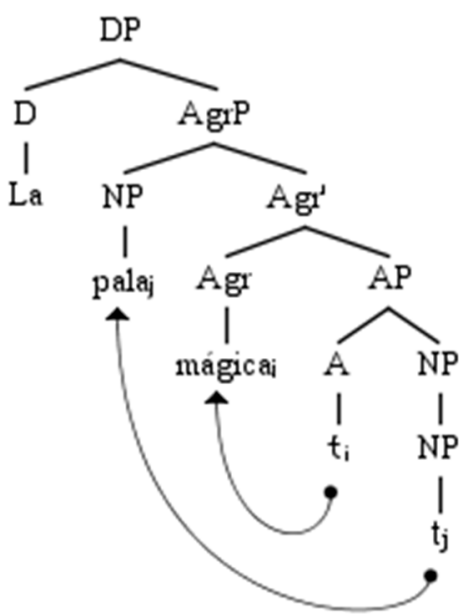

(19) La pala mágica

The shovel magic

'The magic shovel' 


\subsection{The Noun Determines Word Order}

Arnaus Gil et al. (2012) looked at code-switched DPs among bilingual children. In codeswitching contexts, although not explicitly stated, they adopt the assumption that, the noun determines the final order of the DP. In a code-switching context, they predict that if the noun is in Spanish, both AN or NA orders are possible, while if the noun is in German, only the AN order is acceptable. This follows the assumptions detailed above: the AN order should obtain because the noun is German and German nouns do not raise. The only order that is predicted to be ungrammatical is the *N German + A Romance. Therefore, (20) should be ungrammatical according to this approach:

$$
\begin{aligned}
& \text { La Schaufel magica } \\
& \text { The shovel magic } \\
& \text { 'The magic shovel' }
\end{aligned}
$$

(German-Italian)

(Modified, Cantone and MacSwan 2009, p. 268, (16))

Arnaus Gil et al. (2012) analyzed the longitudinal data of 12 children taken from three research projects. All children were bilingual speakers of German and either French, Italian, or Spanish from birth. The average age span was from 1:6 and 5:0 years. They found a total of 129 tokens showing code-switched DPs with an adjective. Instances of the four possible orders were found (21):

(21) (a) 58 tokens of the order: German A + Romance N

(b) 46 tokens of the order: Romance A + German N

(c) 11 tokens of the order: German $\mathrm{N}+$ Romance $\mathrm{A}$

(d) 13 tokens of the order: Romance N + German A

It can be argued that these data suggest that these children prefer the AN order, regardless of language combination, but no option is fully ungrammatical. As previously mentioned, Arnaus Gil et al. (2012) suggest that a German noun followed by a Romance adjective should be ungrammatical, due to the fact that the German noun does not raise above the adjective. Nevertheless, they found 11 examples of this type of switch (21c). In order to clarify these counterexamples, they claim that these instances had come from the unbalanced bilinguals (bilinguals who are more fluent in one language than in the other) in terms of fluency. They believe the noun appears to have moved to the left because the grammatical system of these children is Romance. Thus, they suggest that these examples of a Romance DP with a German noun could be borrowings and that these children borrow the German noun into the Romance lexicon and it is inserted to the syntax as a Romance noun.

However, it is important to note that as they use child data instead of data taken from adults, differences in code switching can occur between adults and children because children's grammar is different from adults'. It can be the case that the grammatical features that underlie the word order options for adjectives are not fully developed yet and this can lead to variation in their results. In addition, the age range of the children that participated in the study is quite considerable.

Furthermore, Arnaus Gil et al. (2012) do not incorporate the division of adjectives established by Bartlett (2013) and Taboada (2010). It is important to determine the type of adjectives used in the experiment. For instance, the authors found that: A Romance + N German was the second most popular sequence. Thus, as in Romance languages, adjectives should appear post-nominally, authors suggest that these results align with their hypothesis that the noun establishes the final adjective-noun ordering. However, we do not know if these adjectives belong to the types of adjectives that can appear pre-nominally (Type 1 or 2/3 adjectives) (as Cinque argues, the same division for Spanish adjectives by Types also holds for the other Romance languages). If some of these adjectives were Type 3 adjectives, they can appear pre-nominally and if this is the case, then the realization of these sequences could also indicate that the adjective is responsible for determining the order and not only that the noun is. 


\subsection{The Adjective Determines Word Order}

Cantone and MacSwan (2009) propose a syntactic structure following Cinque (2005). They argue that in code-switching contexts, the adjective dictates the movement of the noun. They assume in their analysis that there is an AgrP between the DP and the NP. This AgrP is in the language of the adjective and Agr triggers the movement of the noun that raises to spec AgrP in Romance in order to check features. This is illustrated in (22) below. On the other hand, in Germanic languages, noun movement does not happen and the noun checks its features covertly.

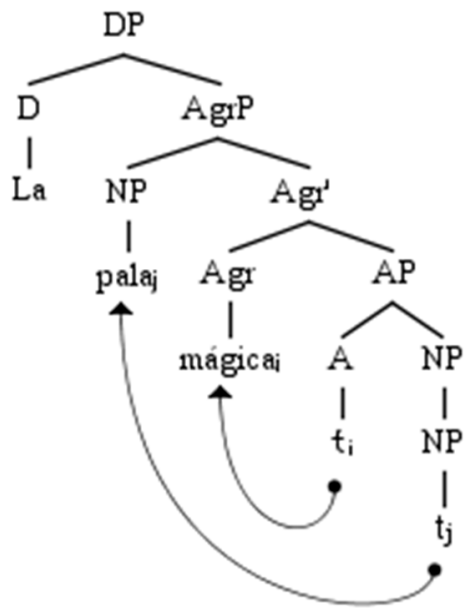

$$
\begin{aligned}
& \text { La pala mágica } \\
& \text { The shovel magic } \\
& \text { 'The magic shovel' }
\end{aligned}
$$

(Modified, Cantone and MacSwan 2009, p. 268, (16))

In code switching contexts, authors assume that if the adjective is in Romance, then Agr is in Romance as well and thus noun movement happens resulting in N German + A Spanish. However, as some Spanish adjectives are pre-nominal (Type 1 adjectives) or can appear pre-nominally (Type 2 and Type 3), the order A Spanish + N German should be allowed with these types of adjectives.

On the other hand, if the adjective is in German, Agr is in German as well, and thus noun movement does not happen and the noun checks its features covertly. Therefore, the noun stays in its position creating the A German + N Spanish order. That is why Cantone and MacSwan (2009) claim that the adjective determines the position of the nounadjective order.

The predictions of this analysis are as follows: if the adjective is a Type 4 Romance adjective, a switch with a Germanic noun in post adjectival position (A Romance $+\mathrm{N}$ Germanic) should be ungrammatical. An example of a switch of this type is found in (23a) below, where americano 'American' is a Type 4 adjective. The reason behind is that if the adjective is Romance, noun movement must happen.

If the adjective is in a Germanic language, then N Romance + A Germanic (23b) should not be allowed. This is because if the adjective is Germanic, noun movement does not happen and the noun must remain in post-adjectival position.
a. Un americano cousin An American cousin
'An American cousin'
b. Una cosa schwerer
A thing difficult
'A difficult thing'
(Spanish-English)
(Spanish-German) 
They tested their predictions with ten German-Italian bilinguals: six females and four males. The age of participants ranged from 29 to 60 years old. All participants reported to have studied in both German and Italian and used both languages actively. The onset of bilingual language exposure ranged from birth to three years old. The survey was presented in written form and participants were asked to judge 22 sentences that consisted of a determiner, a noun, and an adjective.

They found a pattern that indicates that word order was dictated by the adjective because switches such as A German + N Romance (24a) and N German + A Romance (24b) were highly accepted:

$$
\begin{aligned}
& \text { a. Eine alte zia } \\
& \text { An old aunt } \\
& \text { 'An old aunt' } \\
& \text { b. Una Gegend fredda } \\
& \text { A region cold } \\
& \text { 'A cold region' }
\end{aligned}
$$

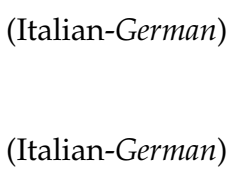

(Cantone and MacSwan 2009, p. 263, (19))

In contrast, switches like (25): A Romance + N German were not highly accepted. That is, when the adjective does not follow the order of its language (Italian adjectives pre-nominally and German adjectives post-nominally), sentences were judged unacceptable (although with 20\% acceptance, which is still quite good).

$$
\begin{aligned}
& \text { Un americano cousin } \\
& \text { An American cousin } \\
& \text { 'An American cousin' }
\end{aligned}
$$

$$
\text { (Italian-German) } \quad \text { (20\% acceptance) }
$$

(Cantone and MacSwan 2009, p. 263, (4))

However, they did not include in their discussion any switch with the sequence $\mathrm{N}$ Romance + A German such as in (26). The acceptability/unacceptability of these switches would have provided useful insights to prove their theory because these switches are predicted to be ungrammatical by their theory.

$$
\begin{aligned}
& \text { Una zia alte } \\
& \text { An aunt old } \\
& \text { 'An old aunt' }
\end{aligned}
$$

(Italian-German)

\section{(Cantone and MacSwan 2009, p. 263)}

In general, their results show variability: there are some sentences judged acceptable by $100 \%$ of the participants but no sentence received a zero and was rejected by all the participants. In addition, only 22 sentences were tested and five of them included a switch between the $\mathrm{D}$ and the $\mathrm{N}$ with no adjective as in (27) which narrows down the switches between a noun and an adjective.

$$
\begin{aligned}
& \text { Mein Vino } \\
& \text { My wine } \\
& \text { 'My wine' }
\end{aligned}
$$

(Italian-German)

(Cantone and MacSwan 2009, p. 263)

Therefore, with such a small sample (ten participants) and variability in the target sentences, no conclusive results can be reached. Furthermore, we do not know if the adjectives were divided by type or if their position in relation to the noun was taken into account and this is key in order to examine all the possible combinations with accuracy.

In addition, consider example (28). According to Cantone and MacSwan's theory, the example in (28) is supposed to be ungrammatical because the adjective is German and if the adjective dictates the order of the DP, it should appear pre-nominally. However, this example appears in Arnaus Gil et al.'s (2012) corpus; Cantone and MacSwan's theory does not account for the appearance of $(28)$ in the corpus. 
$(28)$

$$
\begin{aligned}
& \text { Una cosa schwerer } \\
& \text { A thing heavier } \\
& \text { 'A heavier thing' }
\end{aligned}
$$

(German-Spanish)

(Arnaus Gil et al. 2012, p. 251, (19))

Moro Quintanilla (2016) analyzed code-switched corpus data from English-Spanish bilinguals living in Gibraltar, gathered by Moyer (1992). All the speakers lived in Gibraltar at the time of the study, their ages ranged between 27 and 47 years and there were 17 women and 9 men. She adopts a similar idea to what Cantone and MacSwan propose, namely, that the adjective determines word order in code switched DPs.

The corpus consists of $16 \mathrm{~h}$ of transcripts of spontaneous speech conversations. These conversations were selected because all speakers were bilingual speakers that code switched in their lives. From a total of 1403 nominal constructions, 315 were code-switching utterances and only 54 examples contained a noun and an adjective.

According to Moro Quintanilla, the adjective determines if the noun needs to move or not. If the A is in English, the $\mathrm{N}$ does not need to move overtly. On the other hand, if the A is in Spanish, the N moves overtly. According to Moro Quintanilla (2016), this theory best accounts for the data she found in the corpus:

(30)
(Spanish-English)

(Spanish-English)
'The fresh Christmas trees'

Un brochure nuevo

A brochure new

'A new brochure'

(Moro Quintanilla 2016, p. 27, (8,9))

As seen in examples (29) and (30) above, when adjectives are in Spanish, nouns are always found before the adjective, thus suggesting that as adjectives are in Spanish, they make the noun move overtly creating the DNA order. Nevertheless, there are very few examples in her study, and consequently, it does not allow us to reach relevant conclusions.

In addition, it is important to mention that corpus data are not probative, they offer sentences that are produced in real speech but this does not indicate that the sentences that are not pronounced are ungrammatical. There might be some unattested sentences with different types of adjectives that are grammatical, but not considered because they do not appear in the corpus.

\subsection{The Matrix Language Determines Word Order}

There are some other studies that have analyzed the NA/AN orders in code-switched contexts. These studies have focused on comparing their results under these two standpoints: Cantone and MacSwan's theory, the Adjective Theory, and the Matrix Language Frame model (MLF) (or the Carrier Phrase Theory) (Myers-Scotton 2002). Under the first approach, they assume that the adjective determines word order within the DP, under the latter approach, the matrix language does. According to the Matrix Language Theory, the matrix language (ML) is established by the morphology of the finite verb. This theory predicts that "if the bound morphology of the verb is from Language A, then it is predicted that the word order of an adjective and a noun containing code switching will also be from Language A" (Parafita Couto et al. 2015, p. 67). Indirectly, these approaches test whether the carrier phrase has an influence on determining the noun-adjective order. In this section, we provide a review of these studies.

Parafita Couto et al. (2015) looked at Welsh-English mixed DPs. Welsh and English differ in the position of the adjective. English adjectives are pre-nominal while Welsh adjectives are post-nominal. Consequently, the Adjective Theory predicts that switches such as $\mathrm{N}$ English $+\mathrm{A}$ Welsh and A English $+\mathrm{N}$ Welsh are grammatical while A Welsh $+\mathrm{N}$ English and N Welsh + A English are ungrammatical. In contrast, the ML Theory states that in code-switched DPs, the word order is decided by the matrix language (ML). Thus, if the inflection of the verb is Welsh, the matrix language is Welsh and the stimuli with Welsh 
word order (adjectives appearing post-nominally) should be more acceptable than a word order that does not match Welsh word order. The same should be expected when English is the matrix language.

They tested their research questions in three different studies: for the first study, they used naturalistic data, for the second one, semi-experimental data, and the third study consisted fully of experimental data. For the first part, authors looked at the Siarad corpus collected at Bangor University. It consisted of $40 \mathrm{~h}$ of informal conversation between two English-Welsh bilinguals. They found 137 utterances with noun phrases that included adjectives. All instances had Welsh as their matrix language, thus these sentences should match Welsh word order (postnominal adjectives). Out of the 137 switches, 129 had adjectives in postnominal position (94.1\% of the time). They found seven switches with the order A Welsh + N English and one switch with the order A English + N Welsh that the ML Theory cannot account for.

From the standpoint of the Adjective Theory, the Adjective Theory predicts that only $\mathrm{N}$ English + A Welsh and A English + N Welsh are grammatical. They found 36 instances with the order N Welsh + A English and one switch with the order A Welsh + N English predicted to be ungrammatical by the Adjective Theory. They conclude, thus, that the ML Theory was more accurate in explaining their data than the Adjective Theory.

For the second study, they created a semi-experimental set by making participants complete the director-matcher task. They recruited 50 Welsh-English bilinguals; 77.67\% of the participants reported to have grown up speaking Welsh at home, $9 \%$ English, and $24 \%$ both.

Once again, they found that all the utterances had Welsh as the matrix language. Therefore, according to the ML Theory, the expected order should be NA, regardless of the language, while the Adjective Theory predicts that an English adjective will appear pre-nominally and a Welsh adjective post-nominally. They found these patterns: N English + A Welsh and N Welsh + A English; as observed, in all of them the adjective appeared post-nominally, thus these patterns were correctly predicted by the ML Theory. On the other hand, the order N Welsh + A English cannot be accounted for by the Adjective Theory. They conclude that the ML Theory accurately predicts all the examples they found and thus it is a better predictor of their data.

Finally, their last experiment consisted of 84 code-switched sentences, 36 of which were fillers and practice examples. A total of 50 bilinguals took part in the experiment. The instances were presented orally and the participants were asked to judge each sentence on a four-point scale (three being 'perfectly acceptable' and one being 'totally unacceptable'; participants could also give a zero to the sentences meaning 'I can't decide').

The results showed that when the matrix language was Welsh, sentences with postnominal Welsh adjectives received an average score of $M=1.6$ while post-nominal English adjectives received an average score of $M=1.13$. On the other hand, when the matrix language was English, sentences with prenominal English adjectives had an average score of $M=1.42$ while the average rating for sentences with prenominal Welsh adjectives was $M=1.1$.

The results matched the predictions of the ML Theory in that adjectives are more acceptable when they appear post-nominally with Welsh as the matrix language and prenominally with English as the matrix language. In addition, results also matched the predictions of the Adjective Theory that the adjective determines word order. Thus, authors conclude that these results are not conclusive enough since there is not a preference towards one of the models. Finally, after analyzing the three different sets of experimental data, Parafita Couto et al. (2015) argue in favor of the ML Theory because it can best predict their data.

Vanden Wyngaerd (2016) tested French-Dutch code-switched DPs. As was the case with the previous studies, French and Dutch differ in adjective position: most French adjectives are post-nominal while Dutch adjectives are pre-nominal. For her experiment, 
she selected French adjectives that have the unmarked position post-nominally so that both languages could differ in the position of the adjectives.

Regarding the predictions for the ML Theory, if the matrix language is in French (we know this because in these examples, the verb is in French), the preferred order should be N Dutch + A French (31) and N French + A Dutch (32) because in French adjectives are usually post-nominal. Therefore, participants should accept examples like (31) and (32) and reject examples like (33) in which the NA sequence does not follow French word order.

(31) François fait het bed douillet.

(French-Dutch)

François makes the bed cozy

'François makes the bed cozy.'

(32) L'enfant mange une pomme groene.

The child eats an apple green.

(French-Dutch)

'The child eats a green apple.'

(33) Elle créait de laide jurk.

(French-Dutch)

She created the ugly dress

'She created the ugly dress.'

(Vanden Wyngaerd 2016, p. 85)

On the other hand, if the matrix language is in Dutch, the preferred sequences should be A Dutch + N French (34) and A French + N Dutch (35) and reject examples such as (36) in which Dutch word order is not followed.

(34) In de tuin staat un oude arbre.

(French-Dutch)

In the garden is an old tree

'In the garden there is an old tree'.

(35) Antoine scheert de brune baard.

(French-Dutch)

Antoine shaves the brown beard

'Antoine shaves the brown beard.'

(36) Hij kreeg de fiets lent.

He received a bike slow

‘He received a slow bike.'

(French-Dutch)

(Vanden Wyngaerd 2016, p. 85)

According to the Adjective Theory, examples (33) and (36) above should be unacceptable while example (31), (32), (33), and (34) should be accepted.

She distributed a survey to ten Dutch-French bilinguals using Qualtrics. The survey consisted of 160 sentences, 120 were test sentences and 40 were distractors. The test sentences consisted of three different types of sentences: (1) switches with a $\mathrm{D}$ and a $\mathrm{N}$, (2) complex DPs consisting of switches with a D, N, and A, and (3) distractors. Sentences were inserted in a carrier phrase and participants were asked to judge each sentence as 'unacceptable', 'neither acceptable nor unacceptable', or 'acceptable'. Sentences were presented in oral form. Sentences were coded as 0 for 'unacceptable', 1 for 'neither acceptable nor unacceptable', and 2 for 'acceptable'.

For the type of sentences pertaining code-switched DPs with an adjective, we are not presented with all the data she found and only the main conclusions are reported. She states that the Adjective Theory seems to have better predictions than the ML Theory. According to Vanden Wyngaerd (2016), the sentences that the Adjective Theory predicts to be grammatical had statistically significant higher ratings than those predicted to be grammatical by the ML Theory. She found that out of the 96 sentences, 24 are predicted to be grammatical by the ML Theory and the mean rating of participants' judgments for these sentences is 0.69 . However, the mean ratings for the sentences predicted to be ungrammatical by the ML Theory is 0.72 , higher than the grammatical ones; this indicates that the ML Theory is not a good predictor for her sentences. In contrast, for the sentences predicted to be grammatical by the Adjective Theory, the mean rating is 0.91 while the sentences predicted to be ungrammatical have a mean rating of 0.66 and this difference is significant $(p<0.02)$. Therefore, the sentences predicted to be grammatical by the 
Adjective Theory, have higher ratings than the sentences predicted to be grammatical by the ML Theory.

All in all, Vanden Wyngaerd states that her findings seem to agree with Cantone and MacSwan: the adjective determines the order within the DP. However, we are not provided with a list of the French adjectives. Although she uses post-nominal French adjectives, it could be the case that French also shows the Spanish distribution of adjectives by types and some of them are Type 2 or Type 3 adjectives (they can appear pre-nominally and post-nominally) and thus predictions may differ depending on the type of adjectives. As Vanden Wyngaerd points out, although the unmarked position for French adjectives is post-nominal, some French adjectives can appear pre-nominally and some of them can appear pre-nominally and post-nominally with change in meaning or with no change in meaning as Spanish Type 2/Type 3 adjectives. In particular, she mentions the adjective ancien 'old' that changes in meaning depending on the position in which it appears ( $m a$ femme ancienne 'my old wife' vs. ma ancienne femme 'my ex-wife'). This is something that needs to be taken into consideration since it has a direct effect on the interpretation of the data.

Stadthagen-González et al. (2017) conducted an experiment analyzing noun-adjective word order in Spanish-English code-switching instances. Their goal was, as in the previous studies, to test the predictions of the ML Theory and the Adjective Theory. In order to do so, they used two different methodologies: the AJT and a 2 Alternative Forced Choice task (2AFCT).

Regarding the AJT, they tested 40 early English-Spanish bilinguals. They created two different sets of tokens. In the first set, the verb was in English and the switch went from English to Spanish (37). In the second one, the verb was in Spanish and the direction of the switch went from Spanish to English (38). For each set, there were four different variations of each sentence. There was variation in the language of the noun and in the language of the adjective (Spanish vs. English) and in the word order (pre-nominal vs. post-nominal) $(37 \mathrm{a}-\mathrm{d})$ and $(38 \mathrm{a}-\mathrm{d})$. They also included 48 fillers and 8 quality control trials.
a. I like the marrón dress
b. I like the dress marrón
c. I like the brown vestido
d. I like the vestido brown
(38) a. Me gusta el vestido brown
b. Me gusta el brown vestido
c. Me gusta el dress marrón
d. Me gusta el marrón dress

(Spanish-English)

(Spanish-English)

(Stadthagen-González et al. 2017, p. 8)

It is important to mention that for their experiment, they did not distinguish for adjective type in that they did not use exclusively relational adjectives. As observed in their study, they used some adjectives such as caliente 'hot' or marrón 'brown'. These adjectives are classified as Type 3 adjectives, they are qualifying adjectives and although the unmarked position is post-nominal, these types of adjectives can be used pre-nominally in Spanish (Mantuvieron una caliente discusión 'they had a heated argument'). According to the authors, the Adjective Theory predicts a sentence like 'Necesito un caliente bath' ('I need a hot bath') to be ungrammatical, because adjectives in Spanish need to be post-nominal while the ML Theory predicts this sentence to be grammatical (i.e., matrix language is English and thus English word order should follow). However, as these adjectives are qualifying adjectives (they can appear pre-nominally), a pre-nominal adjective does not necessarily lead to the conclusion that the Adjective Theory is making the wrong prediction. Thus, it is important to select exclusively post-nominal/relational adjectives or, if qualifying adjectives are selected, predictions should be made accordingly.

For the procedure, they distributed the experiment online using Qualtrics. This time, participants were asked to rate each sentence in a 5-point Likert-scale according to how 
acceptable a sentence was. For the results, their assumptions yield the set of predictions illustrated in Table 2.

Table 2. Summary of predictions for Stadthagen-González et al. (2017).

\begin{tabular}{lcc} 
& Adjective Theory & ML Theory \\
\hline a. I like the marrón dress & $x$ & $\checkmark$ \\
b. I like the dress marrón & $\checkmark$ & $x$ \\
c. I like the brown vestido & $\checkmark$ & $\checkmark$ \\
d. I like the vestido brown & $x$ & $x$ \\
\hline
\end{tabular}

All of the sentences in Table 2 have English as the matrix language, thus, both theories would predict (c) to be acceptable: the Adjective Theory because the English adjective appears pre-nominally and the ML Theory because it matches the English word order, that is to say, the English adjective in pre-nominal position. The Adjective Theory predicts (c) and also (b) to be acceptable because the Spanish adjective appears pre-nominally. In contrast, the order does not match English word order and therefore the ML Theory rules out (b). (a) is predicted to be unacceptable by the Adjective Theory because the Spanish adjective appears in prenominal position while it follows English word order and that is why the ML Theory accepts it. Finally, (d) is ruled out by both approaches because neither does it follow English word order nor does the English adjective appear pre-nominally. The same logic applies for sentences with Spanish as the matrix language.

The researchers found that the sentences that are predicted to be acceptable by both models, those in (c), have high ratings while the sentences that are predicted to be ungrammatical by both models are the lowest rated (d). On the other hand, the sentences the Adjective Theory predicts to be acceptable (b) are the second highest although there is no significant difference between the second and the third highest sentences (only predicted to be acceptable by the ML Theory like (a)). Therefore, once again, the results were not conclusive.

They conducted a second experiment using a 2-alternative Forced Choice (2AFC) task. In this task, participants are presented with two sentences and they are asked to choose the closest to the one they would speak. The same 40 early English/Spanish bilinguals that completed the AJT also completed the 2AFC task. The sentences were the same sentences used for their first experiment, but they were compared among themselves: each variation was contrasted with other variation.

They analyzed the results using Thurstone's law ${ }^{2}$. They obtained the same results as with the AJTs, however, in this second experiment, they found a preference for the Adjective Theory over the ML Theory. As with the first experiment, the sentences predicted to be grammatical by the Adjective Theory and the ML Theory were the highest ranked ((c.) I like the brown vestido) and the sentences predicted to be ungrammatical by both models were the lowest rated ((d.) I like the vestido brown). The sentences predicted to be grammatical only by the Adjective Theory were the second highest ranked ((b.) I like the dress marrón) and the third highest ranked were the sentences predicted to be acceptable by the ML Theory ((a.) I like the marrón dress). In fact, this time, they found that these instances ((a) and (b)) were significantly different from each other.

The authors conclude that although both experiments yielded similar results, they claim that the Forced Choice Task revealed that participants show a clear preference for the Adjective Theory. Unlike in Parafita Couto et al. (2015), Stadthagen-González et al. (2017) claim that their data are best explained by the Adjective Theory.

Parafita Couto et al. (2017) investigate noun-adjective orderings with the WelshEnglish language pair. This time they use Event Related Potentials (ERPs) in order to apply neurocognitive methods to linguistic theory.

They tested six conditions divided into six blocks, but the most important conditions for the authors were four. Examples of these four conditions are provided below. 
(39)
A. The bear chased one gwyn horse The bear chased a white horse 'The bear chased a white horse'
B. Helodd yr arth un horse gwyn Chased the bear a horse white' 'The bear chased a white horse'
C. The bear chased a ceffyl white The bear chased a horse white 'The bear chased a white horse'
D. Helodd yr arth un white ceffyl Chased the bear a white horse'
'The bear chased a white horse'

(Matrix Language: English)

(Matrix Language: Welsh)

(Matrix Language: English)

(Matrix Language: Welsh)

(Parafita Couto et al. 2017, p. 245).

The first condition (A) had the matrix language in English and Welsh adjectives in prenominal position. This was predicted to be acceptable by the ML Theory and unacceptable by the Adjective Theory. The second condition (B) had Welsh as the matrix language and Welsh adjectives appeared post-nominally. Condition (B) was predicted to be acceptable by the two models. The third condition $(C)$ is predicted to be unacceptable by the two models because English is the matrix language, and the English adjective appears post-nominally. Finally, the fourth condition (D) has Welsh as the matrix language and English adjectives appear pre-nominally. The ML Theory predicts that (D) is unacceptable while for the Adjective Theory condition (D) is acceptable.

For the procedure, participants were tested individually. The task consisted of reading a sentence presented on the screen and then participants were asked to choose the picture that matched the sentence. Sentences were presented word by word. The independent variable was the ERP signal and the picture masking part was just to have them process language for meaning. There were six experimental blocks and in each of the blocks there were 40 sentences.

For the results, they analyzed conditions (A) and (D). In these conditions, the predictions made by the two models contrast: the ML Theory predicts condition (A) to be grammatical and (D) to be ungrammatical, while the Adjective Theory predicts the opposite. Results show that there is an increased anterior negativity amplitude for the tokens predicted to be ungrammatical by the ML Theory compared to the Adjective Theory. The anterior negativity indicates a syntactic violation and therefore, they conclude that the ML Theory is a better predictor of their data than the Adjective Theory because there is a significant difference between the tokens predicted to be ungrammatical and grammatical by the ML Theory. Nevertheless, they also look at conditions (B) and (C). Both models predict (B) to be acceptable and (C) to be unacceptable, thus, there should be a difference when comparing (B) and (C) conditions. In particular, they should expect the same wordorder violation pattern for condition (C). However, the authors did not find any difference between (B) and (C) which indicates that although the ML Theory can account for the differences between condition (A) and (D), the results are inconclusive.

The authors argue that these results could be due to stimulus repetition. They claim that they had a lot of stimuli and thus, the dynamic of the underlying comprehension mechanisms could have been altered. They, therefore, conclude that this study should be repeated by using more filled sentences and rotating experimental stimuli across participants in order to reduce repetition effects.

Pablos et al. (2018) look at adjective-noun order in Papiamento-Dutch code-switched instances by also using ERPs. As previously argued, in Papiamento adjectives are postnominal, while in Dutch they are prenominal.

A total of 18 highly proficient Papiamento-Dutch bilinguals took part in their experiment. The experiment consisted of 40 sets of six sentences containing a subject, a verb, and an Object. Participants were presented with the sentences in rapid serial visual presentation (RSVP). After each sentence was presented, participants were asked to choose between two pictures, the picture that best depicted the situation portrayed in the sentence. 
Table 3 illustrates an example of a sentence set with all the different conditions and predictions regarding each approach. As observed, condition (A) is rejected by both models, while $(\mathrm{C})$ is accepted by both approaches. On the other hand, (B) is accepted by the ML Theory and rejected by the Adjective Theory while we see the opposite with condition (D).

Table 3. Summary of predictions for Pablos et al. (2018).

\begin{tabular}{|c|c|c|c|c|}
\hline & Example Stimuli & $\begin{array}{c}\text { Matrix } \\
\text { Language }\end{array}$ & $\begin{array}{l}\text { ML Theory } \\
\text { Predictions }\end{array}$ & $\begin{array}{c}\text { Adjective Theory } \\
\text { Predictions }\end{array}$ \\
\hline A. & $\begin{array}{l}\text { De zeehond volgde één kangreu kleine } \\
\text { The sea followed a crab small } \\
\text { 'The sea followed a small crab' }\end{array}$ & $\mathrm{D}$ & $x$ & $x$ \\
\hline B. & $\begin{array}{l}\text { De zeehond volgde één chiki crab' } \\
\text { The sea followed a small crab } \\
\text { 'The sea followed a small crab' }\end{array}$ & $\mathrm{D}$ & $\checkmark$ & $x$ \\
\hline C. & $\begin{array}{l}\text { E foka a sigui un krab chikí } \\
\text { The sea followed a crab small' } \\
\text { 'The sea followed a small crab' }\end{array}$ & $\mathrm{P}$ & $\checkmark$ & $\checkmark$ \\
\hline D. & $\begin{array}{l}\text { E foka a sigui un kleine kangreu } \\
\text { The sea followed a small crab } \\
\text { 'The sea followed a small crab' }\end{array}$ & $\mathrm{P}$ & $x$ & $\checkmark$ \\
\hline
\end{tabular}

(Modified, Pablos et al. 2018, p. 11)

When comparing condition (B) and (D), authors did not find any significant differences between these two sentence conditions. The same was found when comparing condition (A) and (C): No significant effects were found, which indicates that there are no differences between the ERPs elicited by the adjectives in these conditions.

Taking all this into account, the authors concluded that their results do not lend support for any of the approaches: the ML Theory or the Adjective Theory because there was no difference in responses.

\subsection{General Conclusions}

To conclude, in this section, we reviewed several studies that have looked into the problem of noun-adjective ordering within the DP in code switching. There have been three main proposals: (i) the noun gets to determine the final noun-adjective order (Arnaus Gil et al. 2012) (the $\mathrm{N}$ theory); (ii) the adjective does (Cantone and MacSwan 2009) (the A theory); and (iii) the matrix language/carrier phrase establishes the noun-adjective word order (Parafita Couto et al. 2015, 2017; Stadthagen-González et al. 2017) (the ML Theory).

Findings vary. Arnaus Gil et al. (2012) found support for the Noun Theory. Several authors found that the Adjective Theory approach best explains their data (StadthagenGonzález et al. 2017; Vanden Wyngaerd 2016) while others have leaned towards the ML Theory (Parafita Couto et al. 2015, 2017). Table 4 shows a summary of the studies discussed in this section.

The general impression is that no study is conclusive: no study has found robust evidence in favor of one approach over the other and counterexamples have been attested for each of these theories. Furthermore, Spanish has four different types of adjectives: only pre-nominal (Type 1), pre-nominal/post-nominal (Types 2 and 3), and only post-nominal (Type 4). Therefore, predictions regarding code switching are different depending on the adjective type we are analyzing, as these adjectives can appear in different positions. So far, none of the studies reviewed has provided an accurate division or has made explicit that the Romance adjectives selected in their experiment were of one particular type. That is why in some studies (Pablos et al. 2018; Stadthagen-González et al. 2017; Vanden Wyngaerd 2016), the lack of division by adjective type could obscure their results. 
Table 4. Summary of the findings.

\begin{tabular}{ccccc}
\hline Reference & Data Type & Language & Use of Carrier Phrase & Findings \\
\hline Arnaus Gil et al. (2012) & Naturalistic & German/Romance & $\begin{array}{c}\text { Noun Theory best } \\
\text { predicts their data }\end{array}$ \\
\hline Pablos et al. (2018) & ERPs & Papiamento/Dutch & Yes & No conclusive results \\
\hline Parafita Couto et al. (2015) & $\begin{array}{c}\text { Naturalistic } \\
\text { DMT } \\
\text { AJTs }\end{array}$ & Welsh/English & Yes & $\begin{array}{c}\text { ML Theory best } \\
\text { predicts their data }\end{array}$ \\
\hline Parafita Couto et al. (2017) & ERPs & Welsh/English & Yes & $\begin{array}{c}\text { ML Theory best } \\
\text { predicts their data }\end{array}$ \\
\hline Stadthagen-González et al. (2017) & $\begin{array}{c}\text { AJTs } \\
\text { FCT }\end{array}$ & Spanish/English & Yes & $\begin{array}{c}\text { Adjective Theory best } \\
\text { predicts the data }\end{array}$ \\
\hline Vanden Wyngaerd (2016) & AJTs & Dutch/French & Yes & $\begin{array}{c}\text { Adjective Theory best } \\
\text { predicts the data }\end{array}$ \\
\hline
\end{tabular}

Therefore, in this paper, we present a study that tackles this methodological issue and looks into the noun-adjective order problem from a different perspective. We examine the three theories: the N theory, the A theory, and the ML Theory with Spanish/English code-switched DPs by dividing Spanish adjectives in different types taking into account the position in which they can appear. In particular, we analyze Type 4 (only postnominal) and Type 3 ("PRE/POS no change") Spanish adjectives.

\section{Research Questions and Predictions}

The goal of this article is to contribute to our understanding of word order within the DP and, more generally, the theory of syntactic dependencies. We carry out this project via an investigation of code switching. In particular, our research question is as follows.

RQ1: Which category determines the noun-adjective order within the DP?

Based on the previous literature, this research question has been divided in three sub questions that explore the different proposals that have been put forward in the literature. Based on the N theory (Arnaus Gil et al. 2012), the A theory (Cantone and MacSwan 2009; Moro Quintanilla 2016; Vanden Wyngaerd 2016; Stadthagen-González et al. 2017), and the ML Theory (Parafita Couto et al. 2015, 2017), the research questions that this article aims to investigate are the following:

$\mathrm{RQ}$ 1.1. Does the noun (regardless of the other elements) determine adjective-noun order in code-switched DPs?

$\mathrm{RQ}$ 1.2. Does the adjective (regardless of the other elements) determine adjective-noun order in code-switched DPs?

$R Q$ 1.3. If a stimulus contains a carrier phrase, does the carrier phrase influence the noun-adjective order?

Recall that in this experiment, we use English/Spanish data. English has mostly pre-nominal adjectives while Spanish distinguishes four types of adjectives, ranging from pre-nominal to post-nominal adjectives. For this experiment, we use Type 3 Spanish adjectives (adjectives that can appear pre-nominally or post-nominally with no change in meaning) such as tímido 'timid' and Type 4 Spanish adjectives (only post-nominal) such as biológico 'biological' and eléctrico 'electric' and their equivalents in English. Type 4 adjectives will be key because this is where both languages contrast. Type 3 adjectives were also included because they can provide useful answers into the research questions proposed above. In addition, these conditions are accompanied by Spanish carrier phrases and English carrier phrases so that we can test Research Question 1.3.

In order to answer our research questions, we consider the following hypotheses. For Research Question 1.1. (Does the noun (regardless of the other elements) determine adjective-noun order in code-switched DPs?): 
Hypothesis 1. The noun establishes adjective-noun order within the DP (Noun Hypothesis).

This hypothesis follows from what Arnaus Gil et al. found (2012). The data that we use to test Hypothesis 1 are divided by four conditions, as presented in Table 5 . Condition 1 and 2 have the adjective in Spanish and the noun in English. In Condition 1, the adjective appears pre-nominally and in Condition 2 post-nominally. In Conditions 3 and 4, the noun is in Spanish and the adjective is in English. In Condition 3 the order is AN while for Condition 4, the order is NA. Our main interest is to compare Condition 1 with 2 and Condition 3 with 4 . We also take into account the adjective type. The first column represents Type 3 adjectives ('PRE/POS change' adjectives such as timido 'timid') and the second column represents Type 4 adjectives (only post-nominal adjectives).

Table 5. Predictions arising from the Noun Hypothesis.

\begin{tabular}{|c|c|c|}
\hline Type of Stimuli & Type 3 Adjectives & Type 4 Adjectives \\
\hline Condition 1 (ASNE) & $\begin{array}{l}\checkmark \\
\text { Ayer Óscar trajo un blanco duckling } \\
\text { 'Yesterday Óscar brought a white duckling' }\end{array}$ & $\begin{array}{l}\checkmark \\
\text { Esta mañana Leo diseñó un alemán rocket } \\
\text { 'This morning Leo designed a German rocket' }\end{array}$ \\
\hline Condition 2 (NEAS) & $\begin{array}{c}x \\
\text { Ayer Óscar trajo un duckling blanco } \\
\text { 'Yesterday Óscar brought a white duckling' }\end{array}$ & $\begin{array}{c}\boldsymbol{x} \\
\text { Esta mañana Leo diseñó un rocket alemán } \\
\text { 'This morning Leo designed a German rocket' }\end{array}$ \\
\hline Condition 3 (AENS) & $\begin{array}{c}\qquad ? \\
\text { Ayer Óscar trajo un white patito } \\
\text { 'Yesterday Óscar brought a white duckling' }\end{array}$ & $\begin{array}{c}\boldsymbol{x} \\
\text { Esta mañana Leo diseñó un German cohete } \\
\text { 'This morning Leo designed a German rocket' }\end{array}$ \\
\hline Condition 4 (NSAE) & $\begin{array}{c}\checkmark \\
\text { (preferred) } \\
\text { Ayer Óscar trajo un patito white } \\
\text { 'Yesterday Óscar brought a white duckling' }\end{array}$ & $\begin{array}{c}\checkmark \\
\text { Esta mañana Leo diseñó un cohete German } \\
\text { ‘This morning Leo designed a German rocket' }\end{array}$ \\
\hline
\end{tabular}

As suggested in Section 3, we assume the structure proposed by Cinque (1994, 2005, 2010) in which the underlying structure is AN. We further assume that English nouns do not raise, yielding the AN order while Spanish nouns raise leaving the Type 4 adjectives to the right. Noun movement in Spanish can go to a low position, to the right of a Type 3 adjectives, or to a higher position, to the left of the Type 3 adjective.

The assumptions sketched above predict that participants should prefer Condition 1 over 2 for Type 3 and Type 4 adjectives because the English noun will not raise. Consider now Conditions 3 and 4, where the noun is in Spanish. For Type 4 adjectives, participants should prefer Condition 4 over 3 because the noun appears before the adjective creating the NA order. For Type 3 adjectives, both Condition 3 and Condition 4 should be accepted. As the unmarked position for nouns in Spanish is to appear before the adjective, we hypothesize that Condition 4 would be preferred over 3 , although Condition 3 should also be accepted (Condition 3 is marked with a "?" to indicate that although participants should like it, we should see a preference for Condition 4 ).

We also consider Hypothesis 2 for RQ1.1, namely that the noun is not responsible for determining the adjective-noun order contra Arnaus Gil et al. (2012). If this is the case, we should expect a different pattern to what is proposed in Table 5 above.

Now, let us turn our attention to answer Research Question 1.2. For research question 1.2., we consider two hypotheses. Consider Hypothesis 1 first:

Hypothesis 1. The adjective determines adjective-noun word order (Adjective Hypothesis).

This hypothesis follows from Cantone and MacSwan's theory (2009). Following the authors' proposal, we suggest the predictions presented in Table 6. In Table 6, we provide examples of each of the conditions for the reader's convenience. Recall that although 
these examples only contain the carrier phrase in Spanish, for the experiment, we grouped together stimuli with Spanish and English carrier phrases.

Table 6. Predictions arising from the Adjective Hypothesis, divided by adjective type.

\begin{tabular}{|c|c|c|}
\hline Type of Stimuli & Type 3 Adjectives & Type 4 Adjectives \\
\hline Condition 1 (ASNE) & $\begin{array}{c}\qquad ? \\
\text { Ayer Óscar trajo un blanco duckling } \\
\text { 'Yesterday Óscar brought a white duckling' }\end{array}$ & $\begin{array}{c}x \\
\text { Esta mañana Leo diseñó un alemán rocket } \\
\text { 'This morning Leo designed a German rocket' }\end{array}$ \\
\hline Condition 2 (NEAS) & $\begin{array}{c}\checkmark \\
\text { (preferred) } \\
\text { Ayer Óscar trajo un duckling blanco } \\
\text { YYesterday Óscar brought a white duckling' }\end{array}$ & $\begin{array}{l}\checkmark \\
\text { Esta mañana Leo diseñó un rocket alemán } \\
\text { 'This morning Leo designed a German rocket' }\end{array}$ \\
\hline Condition 3 (AENS) & $\begin{array}{c}\checkmark \\
\text { Ayer Óscar trajo un white patito } \\
\text { 'Yesterday Óscar brought a white duckling' }\end{array}$ & $\begin{array}{c}\checkmark \\
\text { Esta mañana Leo diseñó un German cohete } \\
\text { 'This morning Leo designed a German rocket' }\end{array}$ \\
\hline Condition 4 (NSAE) & $\begin{array}{c}x \\
\text { Ayer Óscar trajo un patito white } \\
\text { 'Yesterday Óscar brought a white duckling' }\end{array}$ & $\begin{array}{c}\boldsymbol{x} \\
\text { Esta mañana Leo diseñó un cohete German } \\
\text { 'This morning Leo designed a German rocket' }\end{array}$ \\
\hline
\end{tabular}

As with the previous predictions, we present the data in four different conditions: Conditions 1 and 2 containing Spanish adjectives and Conditions 3 and 4 containing English adjectives. Here again, we compare Condition 1 with 2 and Condition 3 with 4 . First, we report predictions for Type 3 adjectives ('PRE/POS with no change in meaning' such as timido 'timid'). Following the Adjective Hypothesis, when comparing conditions with Spanish adjectives, both Conditions 1 and 2 should be accepted because these adjectives can appear pre-nominally or post-nominally in Spanish monolingual constructions. However, Condition 2 should receive higher ratings because the unmarked position for these adjectives is postnominal. For English adjectives (Condition 3 and 4), Condition 3 (English prenominal adjectives) should be preferred over Condition 4 (English postnominal adjectives) because English adjectives appear pre-nominally.

For Type 4 adjectives (POS only), for conditions with Spanish adjectives, Condition 2 (Spanish adjectives in postnominal position) should be preferred because Spanish Type 4 adjectives can only appear post-nominally. For the conditions with English adjectives, once again, Condition 4 should be rejected and Condition 3 accepted because English adjectives can only appear pre-nominally.

We also consider Hypothesis 2 to RQ1.2.

Hypothesis 2. The adjective does not determine the adjective-noun order.

Finally, the last research question asks whether the carrier phrase influences the noun adjectives order (if the stimuli are presented with a carrier phrase).

For Research Question 1.3., we consider two hypotheses.

Hypothesis 1. If a carrier phrase is present, it has an effect on the adjective-noun word order.

This hypothesis follows from what some previous studies (Parafita Couto et al. 2015, 2017) found. Following the authors' findings, we propose the following predictions presented in Table 7. 
Table 7. Predictions arising from the ML Hypothesis, divided by language of the carrier phrase.

\begin{tabular}{|c|c|c|}
\hline Type of Stimuli & Spanish Carrier Phrase & English Carrier Phrase \\
\hline Condition 1 (ASNE) & $\begin{array}{c}\boldsymbol{x} \\
\text { Ayer Óscar trajo un blanco duckling } \\
\text { 'Yesterday Óscar brought a white duckling' }\end{array}$ & $\begin{array}{l}\checkmark \\
\text { This morning Leo designed an alemán rocket } \\
\text { 'This morning Leo designed a German rocket' }\end{array}$ \\
\hline Condition 2 (NEAS) & $\begin{array}{c}\checkmark \\
\text { Ayer Óscar trajo un duckling blanco } \\
\text { 'Yesterday Óscar brought a white duckling' }\end{array}$ & $\begin{array}{c}\boldsymbol{x} \\
\text { This morning Leo designed a rocket alemán } \\
\text { 'This morning Leo designed a German rocket' }\end{array}$ \\
\hline Condition 3 (AENS) & $\begin{array}{c}x \\
\text { Ayer Óscar trajo un white patito } \\
\text { 'Yesterday Óscar brought a white duckling' }\end{array}$ & $\begin{array}{l}\checkmark \\
\text { This morning Leo designed a German cohete } \\
\text { 'This morning Leo designed a German rocket' }\end{array}$ \\
\hline Condition 4 (NSAE) & $\begin{array}{c}\checkmark \\
\text { Ayer Óscar trajo un patito white } \\
\text { 'Yesterday Óscar brought a white duckling' }\end{array}$ & $\begin{array}{l}\boldsymbol{x} \\
\text { This morning Leo designed a cohete German } \\
\text { 'This morning Leo designed a German rocket' }\end{array}$ \\
\hline
\end{tabular}

In Table 7, we present the predictions for the ML Hypothesis. As with the previous predictions, we present the data in four different conditions: Conditions 1 and 2 containing Spanish adjectives and Conditions 3 and 4 containing English adjectives. Here again, we confront Condition 1 with 2 and Condition 3 with 4 . First, let us consider conditions with a Spanish carrier phrase. Recall that this hypothesis suggests that the adjective-noun order should follow the language of the carrier phrase. Thus, for conditions with a Spanish carrier phrase, conditions with adjectives in post-nominal position should be preferred because in Spanish the unmarked order is noun-adjective. Therefore, Condition 2 (Spanish adjectives in post-nominal position) should be preferred over 1. On the other hand, for conditions with English adjectives, Condition 4 should be preferred over Condition 3 because in Condition 3, adjectives appear in postnominal position.

For conditions that contain English carrier phrases, conditions with adjectives in prenominal position must be preferred. This is because in English, adjectives appear in prenominal position. Thus, for conditions with Spanish adjectives, Condition 1 should be preferred over 2. Finally, regarding conditions with English adjectives, Condition 3 should be preferred over 4 .

We also consider Hypothesis 2 (contra Parafita Couto et al. $(2015,2017)$ ).

Hypothesis 2. The matrix language or the language of the carrier phrase does not have an effect on determining the adjective-noun order. Thus, we should see a different pattern to Table 7.

Based on the literature reviewed on Section 3, we expect the Adjective Hypothesis to be true. That is, that the adjective determines word order within the DP. Several studies have found that the adjective determines word order within the DP (Cantone and MacSwan (2009); Moro Quintanilla (2016); Vanden Wyngaerd (2016); and Stadthagen-González et al. (2017)) and we expect this study to go along the same path.

\section{Materials and Methods}

\subsection{Participants}

A total of 30 early Spanish-English bilinguals were recruited for this study, from which 6 were male and 24 female. Participants ranged in age from 18 to $25(M=21.1$, $S D=2.12$ ). All speakers were living in the Chicago area at the time of the study. A total of 27 participants were undergraduate students and 3 of them were in graduate college. All participants acquired Spanish before the age of 5 (the average age of acquisition for Spanish was $M=0.93$ and the $S D=1.63$ ). For English, all participants acquired the language before the age of 8 , with the average age of acquisition being $M=4.93, S D=3.19$. All participants grew up in bilingual households and all reported using Spanish at home with their parents. 
In order to determine participants' language background and dominance, we used the Bilingual Language Profile questionnaire (BLP) (Birdsong et al. 2012). Most of the participants were English dominant, only six participants were classified as Spanish dominant. The scores ranged from 74.40 to $-68.55(M=22.11, S D=31.72)$. In this questionnaire, participants also had to self-report their reading, speaking, listening, and understanding proficiency of Spanish and English on a scale of one to six, one being 'not well at all' and six being 'very well'. Self-rated proficiency scores are shown in Table 8 below.

Table 8. Average self-ratings for overall and individual skills in Spanish and English.

\begin{tabular}{ccc}
\hline & English & Spanish \\
\hline & $M(S D)$ & $M(S D)$ \\
{$[\mathrm{CI}]$} & $5.06(1.04)$ \\
Reading & {$[\mathrm{CI}]$} & {$[4.69-5.43]$} \\
\hline Writing & $5.63(0.55)$ & $4.6(1.00)$ \\
& {$[5.43-5.82]$} & {$[4.24-4.95]$} \\
\hline Speaking & $5.33(0.84)$ & $5(0.83)$ \\
\hline Understanding & {$[5.03-5.63]$} & {$[4.70-5.29]$} \\
\hline \multirow{2}{*}{ Overall } & $5.40(0.85)$ & $5.56(0.67)$ \\
{$[5.09-5.70]$} & $5.67(0.54)$ & $5.32-5.80]$ \\
\hline
\end{tabular}

Proficiency was assessed by completing a proficiency test for Spanish and English, each of their monolingual varieties. For Spanish, they took a modified version of the DELE (Diploma de Español como Lengua Extranjera, 'Diploma of Spanish as a foreign language'). The highest DELE score was 46 and the lowest score 28 (out of 50), the average being $M=38.66, S D=5.06$.

With regard to English, participants took an excerpt from the Oxford Test of English (as in Slabakova et al. 2016). The scores ranged between 34 and 49 out of 50, the average being $M=41.7, S D=3.83$. All participants had to get a score of 25 or higher on both exams in order to be considered. Participants that scored below 25 were excluded because this indicates "low proficiency".

Finally, in order to establish if participants are indeed code switchers, they filled out an additional questionnaire (Badiola et al. 2018). This questionnaire included information of their usage of code-switching with family and friends, questions about their parents in order to control for dialectal variation, as well as questions about their attitudes towards code switching. All participants were reported code switchers and had good attitudes towards code switching.

\subsection{Task and Stimuli}

For this experiment, participants carried out an AJT. The critical stimuli for this experiment consisted of 320 code switched sentences that were made of an adverb, a subject, a verb, and an object. The target DPs appeared in object position. These target DPs consisted of a determiner, a noun, and an adjective.

For the adjectives, we selected 20 Type 3 adjectives ("PRE/POS no change" such as timido 'timid') and 20 Type 4 adjectives (POS only, such as biológico 'biological'). As discussed, this paper offers a new way of looking into the noun-adjective ordering problem by adopting a division of adjective types according to their position in relation to the noun. This division of adjectives has not been considered in the code switching literature. Type 4 adjectives are essential for this experiment because Type 4 adjectives are always post-nominal in Spanish while in English they are pre-nominal. Thus, code switching between a noun and an adjective of this type will provide important insights about what 
element establishes the placement of the adjective in relation to the noun. Type 3 Spanish adjectives should behave differently than Spanish Type 4 adjectives and this can provide additional data to confirm the results. The selected adjectives for Type 3 and Type 4 can be found in Table 9.

Table 9. Adjectives selected for the target DPs (in alphabetical order).

\begin{tabular}{cc}
\hline Type 3 & Type 4 \\
\hline ambicioso 'ambitious' & alemán 'German' \\
angustioso 'anguishing' & biológico 'biological' \\
blanco 'white' & chino 'Chinese' \\
bonito 'beautiful' & científico 'scientific' \\
brillante 'shiny' & crónico 'chronic' \\
doloroso 'painful' & entero 'whole' \\
dulce 'sweet' & español 'Spanish' \\
encantador 'charming' & ético 'ethic' \\
eterno 'eternal' & financiero 'financial' \\
gracioso 'funny' & físico 'physical' \\
hermoso 'lovely' & francés 'French' \\
peligroso 'dangerous' & marrón 'brown' \\
pequeño 'little' & mecánico 'mechanical' \\
pesado 'heavy' & nocturno 'nocturnal' \\
ruidoso 'noisy' & peruano 'Peruvian' \\
sabroso 'tasty' & politico 'political' \\
silencioso 'quiet' & químico 'chemical' \\
simpatico 'likeable' & ritmico 'rhythmic' \\
sospechoso 'suspicious' & rubio 'blonde' \\
suave 'fluffy' & técnico 'technical'
\end{tabular}

The adjectives and nouns selected were chosen from the 5000 most common Spanish words taken from Davies (2006). Additionally, all adjectives and nouns in Spanish and English ranged from five to ten letters long. Cognates were avoided, including any items with identical orthography. In addition, we included random by item effects that account for any variance that may come from words that are more of a cognate than others. We made sure that all Type 3 adjectives were qualifying adjectives and that all Type 4 adjectives corresponded to relational adjectives.

In order to test the effects of the carrier phrase, the target DPs were accompanied by a carrier phrase. We included DPs with Spanish carrier phrases and the same DPs with English carrier phrases. Based on the previous literature, we can conclude that the D does not play a role in determining the noun-adjective order. Therefore, we did not analyze the effects of the determiner. However, the tokens included a determiner so that they can sound more natural. The determiners were considered part of the carrier phrase, thus if the carrier phrase was Spanish, the Spanish determiner un 'one' was used and when the carrier phrase was English, the determiner 'a/an' was included. Regarding the nouns, all nouns were masculine (el vestido 'dress', el libro 'book') (Stadthagen-González et al. 2017). Example of the stimuli can be found in the example (40) below:

(40) Ayer por la mañana Ana levantó un pesado mattress Yesterday morning Ana lifted a heavy mattress

'Yesterday morning Ana lifted a heavy mattress'

In total, we tested four different conditions that are found in Table 10 below. Condition 1 and 2 had Spanish adjectives and English nouns. In Condition 1, the adjective appears pre-nominally and in 2 post-nominally. Condition 3 and 4 had English adjectives and Spanish nouns; in Condition 3, adjectives were in prenominal position, while in 4 they appeared in postnominal position. 
Table 10. Summary of conditions for the experiment.

\begin{tabular}{cccc}
\hline Condition & Adjective Language & Adjective Position & Sequence \\
\hline Condition 1 & Spanish Adjective & $\begin{array}{c}\text { Adjective prenominal } \\
\text { Adjective postnominal }\end{array}$ & $\begin{array}{c}\text { Adjective Spanish + Noun English } \\
\text { Noun English + Adjective Spanish }\end{array}$ \\
\hline Condition 2 & English Adjective & $\begin{array}{c}\text { Adjective prenominal } \\
\text { Adjective postnominal }\end{array}$ & $\begin{array}{c}\text { Adjective English + Noun Spanish } \\
\text { Noun Spanish + Adjective English }\end{array}$ \\
\hline
\end{tabular}

As each of the conditions was accompanied by a carrier phrase, in total, there were eight possible combinations for each adjective: the four different conditions with a Spanish carrier phrase and the same four conditions with an English carrier phrase. An example of the full configuration is observed in Table 11 below.

Table 11. Combinations used for the experiment.

\begin{tabular}{|c|c|c|c|c|c|c|c|c|c|c|c|c|c|c|}
\hline \multicolumn{8}{|c|}{ Spanish Carrier Phrase } & \multicolumn{7}{|c|}{ English Carrier Phrase } \\
\hline \multirow{4}{*}{ Condition 1} & \multicolumn{7}{|c|}{ Adjective Spanish + Noun English } & \multicolumn{7}{|c|}{ Adjective Spanish + Noun English } \\
\hline & $(41)$ & Ayer & Óscar & trajo & un & blanco & duckling & $(42)$ & Yesterday & Ana & brought & a & blanco & duckling \\
\hline & & Yesterday & Óscar & brought & a & white & duckling= & & Yesterday & Ana & brought & $\mathrm{a}$ & white & duckling \\
\hline & & 'Yesterday & Óscar & brought & $\mathrm{a}$ & white & duckling' & & 'Yesterday & Ana & brought & $\mathrm{a}$ & white & duckling' \\
\hline \multirow{4}{*}{ Condition 2} & \multicolumn{7}{|c|}{ Noun English+ Adjective Spanish } & \multicolumn{7}{|c|}{ Noun English + Adjective Spanish } \\
\hline & $(43)$ & Ayer & Óscar & trajo & un & duckling & blanco & $(44)$ & Yesterday & Ana & brought & $\mathrm{a}$ & duckling & blanco \\
\hline & & Yesterday & Óscar & brought & $\mathrm{a}$ & duckling & white & & Yesterday & Ana & brought & a & duckling & white \\
\hline & & 'Yesterday & Óscar & brought & $\mathrm{a}$ & white & duckling' & & 'Yesterday & Ana & brought & a & white & duckling' \\
\hline \multirow{4}{*}{ Condition 3} & \multicolumn{7}{|c|}{ Adjective English + Noun Spanish } & \multicolumn{7}{|c|}{ Adjective English + Noun Spanish } \\
\hline & $(45)$ & Ayer & Óscar & trajo & un & white & patito & $(46)$ & Yesterday & Daniel & brought & a & white & patito \\
\hline & & Yesterday & Óscar & brought & a & white & duckling & & Yesterday & Daniel & brought & $\mathrm{a}$ & white & duckling \\
\hline & & 'Yesterday & Óscar & brought & $\mathrm{a}$ & white & duckling' & & 'Yesterday & Daniel & brought & a & white & duckling' \\
\hline \multirow{4}{*}{ Condition 4} & \multicolumn{7}{|c|}{ Noun Spanish + Adjective English } & \multicolumn{7}{|c|}{ Noun Spanish + Adjective English } \\
\hline & $(47)$ & Ayer & Óscar & trajo & un & patito & white & $(48)$ & Yesterday & Daniel & brought & $\mathrm{a}$ & patito & white \\
\hline & & Yesterday & Óscar & brought & $\mathrm{a}$ & duckling & white & & Yesterday & Daniel & brought & a & duckling & white \\
\hline & & 'Yesterday & Óscar & brought & $\mathrm{a}$ & white & duckling' & & 'Yesterday & Daniel & brought & $\mathrm{a}$ & white & duckling' \\
\hline
\end{tabular}

In total, we had 160 tokens for Type 3 adjectives and 160 tokens for Type 4 adjectives. All the tokens were created by the author, a native Spanish speaker, and side by side with two bilingual consultants belonging to the communities under study (i.e., two highly proficient English/Spanish bilinguals in the United States).

Each participant judged 40 sentence frames (20 Type 3 sentence frames and 20 type 4 sentence frames from which ten had a Spanish carrier phrase and ten an English carrier phrase). There were 40 items per condition for Type 3 and Type 4 adjectives, however, each participant, saw five items per condition for each adjective type. In addition, participants saw each adjective in only one of the conditions presented above and no adjective was repeated. That is, participants did not see an adjective twice and no sentence frame was repeated (Cowart 1996). In total, we had eight versions of the experiment, and each experiment was answered by four participants (except for two versions that were answered by three participants).

We also included monolingual sentences, sentences in which the adjective and the noun are in the same language. In this case, these sentences were in Spanish, so that we could confirm that these heritage speakers cannot use a Type 4 adjective pre-nominally in Spanish (Camacho 2018). These sentences were the same sentences used in the experiment with Type 4 adjectives but this time, they were all monolingual. This was done in order to ensure that any degraded ratings are not due to the stimuli being in code switching but, rather, due to the fact that these adjectives cannot appear in pre-nominal position. Monolingual sentences using Type 3 adjectives were not included; this is because it would not provide any information regarding the behavior of these adjectives. An example of the monolingual sentences used is found in (49). We had a total of 40 monolingual sentences (each Type 4 adjective (20 in total) appearing pre-nominally and post-nominally). This 
means that for the monolingual stimuli, participants saw repeated adjectives on sentence frames (49).

(49) a.

b.

$\begin{array}{cc}\text { Ayer } & \text { Oscar } \\ \text { Yesterday } & \text { Óscar } \\ \text { 'Yesterday } & \text { Óscar } \\ \text { Ayer } & \text { Oscar } \\ \text { Yesterday } & \text { Óscar } \\ \text { 'Yesterday } & \text { Óscar }\end{array}$

trajo
brought
brought
trajo
brought
brought

patitio
duckling
white
blanco
white
white

blanco white duckling' patitio duckling duckling'.

Finally, distractors were included in order to draw the attention away from the target stimuli. We included the same amount of distractors as target DPs, that is, we included 40 distractors in each experiment. The distractors were designed to test a totally different structure, namely pro drop (Sande 2018). In total, each participant had to judge 40 target sentences, 40 distractors, and 40 monolingual sentences.

\subsection{Procedure}

The experiment followed the standards suggested in González-Vilbazo et al. (2013). Each participant came to the laboratory and took the survey there. The experiment was created using Qualtrics, an online service designed for data collection and storage. Prior to the experimental task, participants signed a consent form. The experiment consisted of five blocks: (1) an AJT in CS, (2) an AJT in monolingual Spanish, (3) the Bilingual Language Profile, (4) the Spanish proficiency test, and (5) the English proficiency test.

First, participants completed the acceptability judgment task in which participants had to judge each sentence in a 1-7 Likert scale, one being the most unacceptable and seven being the most acceptable. Participants were given detailed explanations and instructions about how to perform the Acceptability Judgment Task. This was followed by a practice sentence so that we could make sure that participants understood the task and they knew what they were supposed to do. Instructions were shown in code switching. As suggested in González-Vilbazo et al. (2013), it is important that participants see instructions in code switching in order to provide the adequate environment and activate both languages. The order of the stimuli and presentation of stimuli was counterbalanced and pseudorandomized in order to control for fatigue effects.

The AJT was divided in two blocks: first, participants completed the code-switched AJT (distractors + target sentences) and after this was done, they completed the monolingual AJT. It is important for participants to be tested in code switching mode first because participants seem to prefer monolingual stimuli to CS stimuli (González-Vilbazo et al. 2013). In addition, by doing this, the chance to priming can be reduced (Stefanich 2019).

This section was followed by the BLP questionnaire, in which participants were asked questions about their background. Once they completed the BLP, participants took both proficiency tests: the DELE and the Oxford test in English.

\subsection{Data Analysis}

In order to analyze the results, the average of the ratings and standard deviations were calculated for the four different conditions for the two different adjective types. The participants' individual judgments could not be z-scored (Schütze and Sprouse 2013) because the model did not converge when using z-scores ratings and instead, the AJT ratings were used as the dependent variable. The non-convergence of the data could be due to the z-score transformation. Schütze and Sprouse (2013) suggested that z-score transformation is recommendable when using judgment data with numerical scales. When applying this transformation, the score gets normalized and it makes every participant's mean rating zero and expresses their judgments in terms of standard deviations from that mean. However, this transformation also removes individual variation. Thus, this makes that the random intercept by subject cannot be applied because every subject's mean rate is the same (that is to say zero). Because of this, the raw AJ scores had to be used as the dependent variable. 
For data analysis, five linear mixed model analyses were run. Mixed models for confirmatory hypothesis testing have been widely employed in the literature. According to Linck and Cunnings (2015) "mixed-effects models provide researchers with a powerful statistical tool in the analysis of a variety of different types of data" (Linck and Cunnings 2015, p. 201). One of these advantages is that mixed-effects models allow the inclusion of participant and item level intercepts that can account for individual differences between participants, something that may be disregarded with other types of analyses (Linck and Cunnings 2015).

First, in order to answer Research Question 1.1. and 1.2., we conducted two different analyses. For Type 4 adjectives, a two-factor linear mixed model was conducted, with ratings as the dependent variable and with adjective position (pre vs. pos) and adjective language (Spanish vs. English) being the fixed effects. The same analysis was conducted for Type 3 adjectives.

If results showed an interaction, we followed up the analysis with a within language analysis. That is, we compared conditions that have Spanish adjectives (Condition 1 with 2) and conditions that have English adjectives (Condition 3 with 4). These conditions, as discussed, differ on the position of the adjective with respect to the noun, but the language of the adjective in Condition 1 and 2 and Condition 3 and 4 is the same. Thus, the comparisons between these conditions revealed if there is a preference for a particular order and if this is due to a particular element.

In addition, in order to answer Research question 1.3. and to test if the carrier phrase could have an effect, we conducted another two-factor linear mixed model, with ratings as the dependent variable and with adjective position (pre vs. pos), adjective language (Spanish vs. English), and language of the carrier phrase (Spanish vs. English) as fixed effects. As with the previous analysis, if results showed an interaction, we followed up our analysis with a within language analysis. That is, we compared conditions that have Spanish adjectives (Condition 1 with 2) and conditions that have English adjectives (Condition 3 with 4).

\section{Results}

In order to answer the research questions, the two different adjective types were examined separately. In order to answer Research Question 1.2 (the adjective establishes the final adjective-noun order) it is necessary to separate the adjective by type. This is because if the adjective determines the final adjective-noun order, the type of adjective should matter because there are different predictions depending on the type of adjective. First, we report results for Type 4 adjectives and then for Type 3 adjectives.

\subsection{Results for Type 4 Adjectives}

First, we examined Type 4 adjectives. In the following Table 12, we repeat the predictions for these adjectives. The "adjective" column represents the predictions following the Adjective Hypothesis, namely that the adjective establishes the adjective-noun order. In contrast, the "noun" column represents the Noun Hypothesis (the predictions derived if the noun establishes the adjective-noun order).

First, take a look at Conditions 1 and 2. In these conditions, the adjective is Spanish, in 1 appearing pre-nominally and in 2 post-nominally. Recall that these adjectives (Type 4) can only appear post-nominally in monolingual Spanish constructions. Thus, following the Adjective Hypothesis, when comparing Conditions 1 and 2, Condition 2 (Spanish adjectives in postnominal position) should be preferred over 1 because Spanish adjectives can only appear post-nominally. For the Noun Hypothesis, the opposite should happen, that is, Condition 1 should be preferred over 2 because English nouns appear after the adjective.

Now consider Conditions 3 and 4. In these conditions, the adjective is English, in 3 the adjective appears pre-nominally and in 4 post-nominally. If the adjective is responsible for determining the adjective-noun order, Condition 3 should be preferred over 4, because 
English adjectives appear in prenominal position. On the other hand, if the noun is responsible, then Condition 4 should receive higher ratings than Condition 3.

Table 12. Predictions arising from the Adjective and Noun Hypothesis, for Type 4 adjectives.

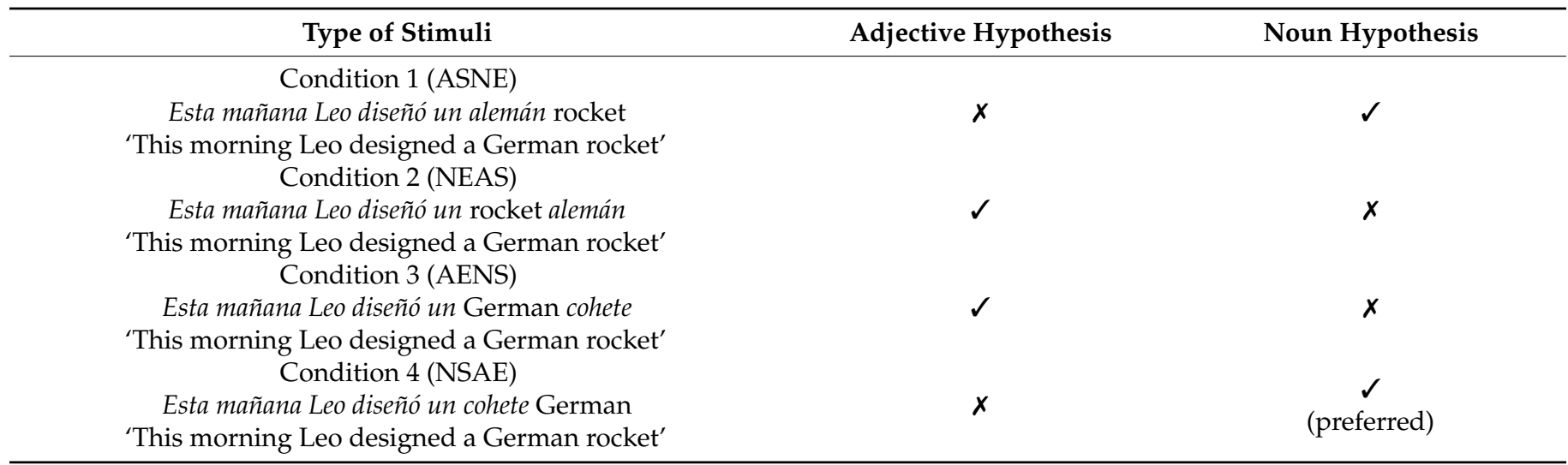

Table 13 shows the mean overall rating for each condition on the 1-7 Likert scale, SDs and $95 \%$ Confidence Intervals. This is collapsed across both carrier phrase languages.

Table 13. Ratings for Type 4 adjectives on the 1-7 Likert Scale.

\begin{tabular}{cccc}
\hline Type of Stimuli & Average Score & SD & 95\% CI \\
\hline Condition 1 (ASNE) & 2.91 & 2.06 & {$[2.58,3.23]$} \\
Condition 2 (NEAS) & 4.32 & 2.39 & {$[3.94,4.69]$} \\
Condition 3 (AENS) & 3.81 & 2.23 & {$[3.45,4.16]$} \\
Condition 4 (NSAE) & 3.53 & 2.26 & {$[3.17,3.88]$} \\
\hline
\end{tabular}

Results for Type 4 adjectives show that Condition 2 received the highest ratings while Condition 1 was the lowest rated. When comparing conditions between them, we see that Condition 2 is preferred over 1 and Condition 3 is preferred over 4 . A visual comparison of the ratings is given in Figure 1 below.

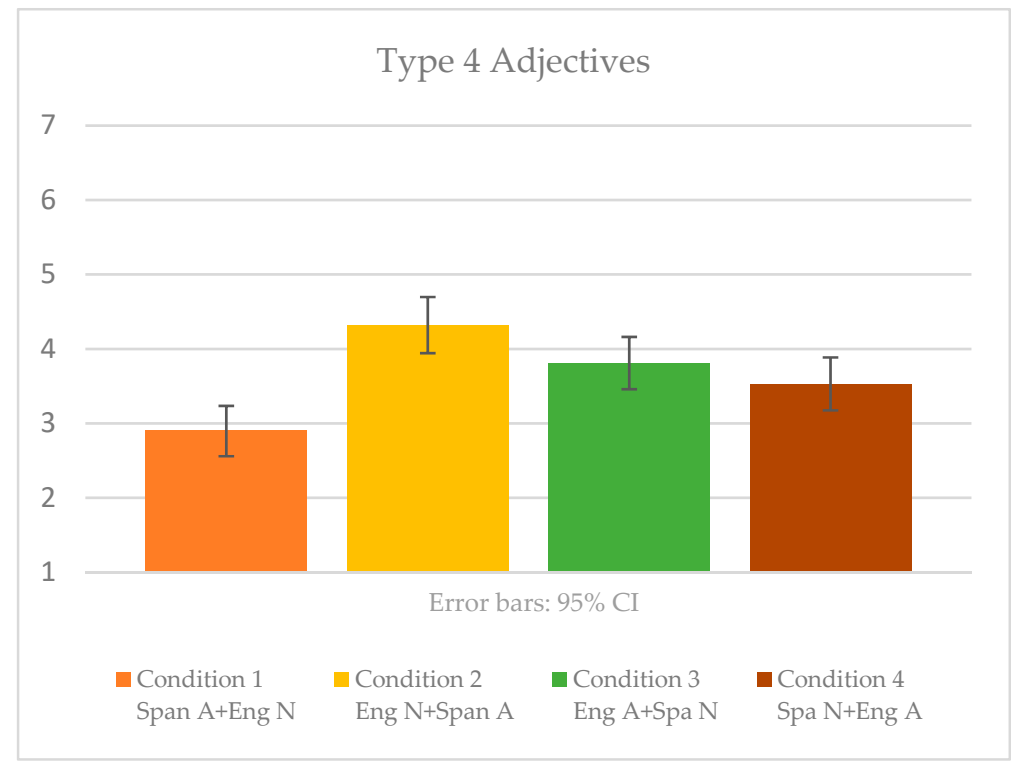

Figure 1. Ratings for all participants by condition for Type 4 adjectives. 
The AJT ratings were fit to General Linear Mixed Model (LMM) using the MIXED procedure in SPSS 24 with ratings as the dependent variable (on a scale of one to seven), adjective language (English vs. Spanish) and adjective position (pre vs. pos) as fixed effects. This was done in order to determine the effect of the conditions on the AJT ratings. We started the analysis with the maximal structure (see Barr et al. 2013). This included random intercepts at the subject and item levels in order to account for individual variation as well as for any variation in the independent variables (i.e., adjective language and adjective position) across items. It also included a random by-subject slope over the fixed effects. The maximal model that converged included random intercepts at the subject levels. It also included a random by-subject slope over the fixed effects.

Significant effects were found for the interaction AdjectiveLanguage*AdjectivePosition $(\mathrm{F}(1,540.060)=33.440, p<0.001)$; that is, participants responded differently depending on the language of the adjective and the position of the adjective.

Since the comparison between Condition 1 and 2 and Condition 3 and 4 is our main interest, a pairwise comparison was performed. We report effect sizes via Hedges' g; small medium, and large effect sizes correspond to values of 0.60, 1.00, and 1.40 (Plonsky and Oswald 2014). According to Stefanich and Cabrelli-Amaro (2018), the use of Hedges'g rather than Cohen's d "corrects for bias yielded by small sample sizes".

Analysis for the pairwise comparisons confirmed that participants gave significantly higher ratings to Condition 2 (adjectives in Spanish appearing post-nominally) than to Condition 1 (Spanish adjectives appearing pre-nominally) $(p<0.001)$. Statistically speaking, participants showed a preference for Condition 2, that is, participants preferred Spanish adjectives appearing post-nominally, although the size of the effect was small $(g=0.68)$. For Conditions 3 and 4, that is, when the adjective is English, participants gave slightly higher ratings to sentences where the English adjective appears pre-nominally (Condition 3 ) than post-nominally (Condition 4$)$, but this difference was not significant $(p=0.220),(\mathrm{g}=0.12)$.

Overall, the pattern observed maps into the predictions derived by the Adjective Hypothesis, although this pattern is more clearly observed with Spanish adjectives than with English adjectives.

\subsection{Results for Type 3 Adjectives}

The same procedure used to analyze results for Type 4 adjectives was used with Type 3 adjectives. This time, we grouped Type 3 adjectives in Spanish and their equivalents in English. Type 3 adjectives are adjectives that can appear pre-nominally or post-nominally in Spanish with no change in meaning.

Consider Table 14. In this table, the predictions for Type 3 adjectives are presented. Here again, we divide them by the "Adjective Hypothesis" and the "Noun Hypothesis", first and second column, respectively. In Condition 1 and 2, the adjective appears in Spanish and the noun is English. In Condition 1, the adjective appears in pre-nominal position, while in 2, it appears post-nominally.

If the adjective establishes the final adjective-noun order, Condition 2 should be preferred over Condition 1, although the difference between these two conditions should be small. This is because the unmarked position of these adjectives is postnominal; however, the prenominal position is also allowed. In addition, the difference between these two conditions should be bigger with Type 4 adjectives than with Type 3 adjectives because Type 4 Spanish adjectives are restricted to postnominal position. According to the Noun Hypothesis, on the other hand, Condition 1 should be preferred over 2, because as stated before, English nouns appear after the adjective.

For conditions where the adjective is English (3 and 4), following the Adjective Hypothesis, Condition 3 should receive higher ratings than Condition 4 . On the other hand, if the noun were to determine the final AN/NA order, both conditions should be preferred, although we should see a preference towards Condition 4, because nouns in Spanish can appear before or after the adjective, although the unmarked position is for the noun to appear before the adjective. 
Table 14. Predictions arising from the Adjective and Noun Hypothesis, for Type 3 adjectives.

\begin{tabular}{|c|c|c|}
\hline Type of Stimuli & Adjective Hypothesis & Noun Hypothesis \\
\hline Condition 1 (ASNE) & \multirow{3}{*}{$\checkmark ?$} & \multirow{3}{*}{$\checkmark$} \\
\hline Ayer Óscar trajo un blanco duckling & & \\
\hline 'Yesterday Óscar brought a white duckling' & & \\
\hline Condition 2 (NEAS) & \multirow{3}{*}{$\begin{array}{c}\checkmark \\
\text { (preferred) }\end{array}$} & \multirow{3}{*}{$x$} \\
\hline Ayer Óscar trajo un duckling blanco & & \\
\hline $\begin{array}{c}\text { 'Yesterday Óscar brought a white duckling' } \\
\text { Condition } 3 \text { (AENS) }\end{array}$ & & \\
\hline Ayer Óscar trajo un white patito & \multirow{2}{*}{$\checkmark$} & \multirow[t]{2}{*}{$\checkmark ?$} \\
\hline 'Yesterday Óscar brought a white duckling' & & \\
\hline Condition 4 (NSAE) & \multirow{3}{*}{$x$} & \multirow{3}{*}{$\begin{array}{c}\checkmark \\
\text { (preferred) }\end{array}$} \\
\hline Ayer Óscar trajo un patito white & & \\
\hline 'Yesterday Óscar brought a white duckling' & & \\
\hline
\end{tabular}

Table 15 shows the mean overall rating for each condition on the 1-7 Likert scale, SDs and $95 \%$ Confidence Intervals (the stimuli contain conditions with Spanish and English carrier phrases collapsed).

Table 15. Ratings for Type 3 adjectives on the 1-7 Likert scale.

\begin{tabular}{cccc}
\hline Type of Stimuli & Average Score & SD & $\mathbf{9 5 \% ~ C I ~}$ \\
\hline Condition 1 (ASNE) & 3.58 & 2.31 & {$[3.21,3.94]$} \\
Condition 2 (NEAS) & 4.12 & 2.20 & {$[3.77,4.46]$} \\
Condition 3 (AENS) & 4.41 & 2.24 & {$[4.05,4.76]$} \\
Condition 4 (NSAE) & 3.36 & 2.29 & {$[3.00,3.72]$} \\
\hline
\end{tabular}

Results for Type 3 adjectives reveal that Condition 3 is the highest rated condition while Condition 4 received the lowest ratings. When comparing between conditions, we can see that Condition 2 is preferred over 1 and Condition 3 over 4 . A visual comparison of the ratings is given in Figure 2 below.

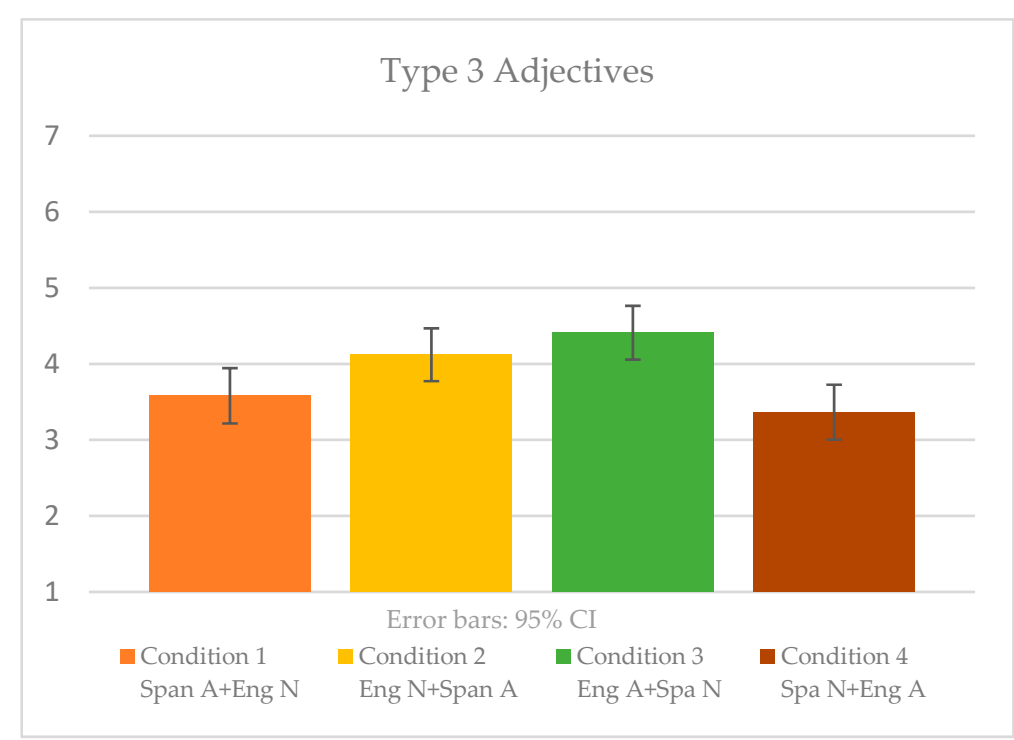

Figure 2. Ratings for all participants by condition for Type 3 adjectives.

Another Linear Mixed Model was run using the MIXED procedure in SPSS 24 with Type 3 adjectives ratings as the dependent variable (on a scale of one to seven) and adjective language and adjective position as fixed effects. This was done in order to determine the effect of the conditions on the AJT ratings. The random effects structure was the maximal 
structure supported by the data (see Barr et al. 2013). Linck and Cunnings (2015) suggest that for confirmatory hypothesis testing, maximal models should be adopted because the maximal structures "have the best potential to produce generalizable results". Random intercepts were included at the subject and item levels in order to account for individual variation as well as for any variation in the independent variables (i.e., adjective language and adjective position) across items. A random by-subject slope over the fixed effects was also included.

A significant effect was found for AdjectiveLanguage*AdjectivePosition $(\mathrm{F}(1,536.968)$ $=27.589, p<0.001)$. Once again, as our aim is to compare Condition 1 and 2 and Condition 3 and 4 , we performed a pairwise contrast which confirmed that participants gave significantly different ratings to different conditions.

For Type 3 adjectives, the pairwise comparison confirms that participants preferred Condition $2(p<0.011)$, although the size of the difference between Condition 1 and 2 was very small $(g=0.24)$. That is, participants preferred sentences in which the Spanish adjectives appeared in postnominal position (Condition 2) than in prenominal position (Condition 1) although with a very small effect size. These results align with the Adjective Hypothesis.

Second, we will consider the interaction between Condition 3 and 4, that is, English adjectives appearing pre-nominally (Condition 3) and post-nominally (Condition 4 ). The pairwise comparison reveals a significant difference between these two conditions $(p<0.001)$ approaching a small effect size $(g=0.46)$.

Overall, the data match the predictions derived from the Adjective Hypothesis rather than the Noun Hypothesis, although the differences and the effect sizes are small. An in-depth discussion of the results is provided in Section 7. First, however, in the next section (Section 6.3) we present the results obtained for the ML Hypothesis.

\subsection{Results for the Matrix Language Theory}

In this section, we provide an analysis in order to test whether the carrier phrase influences the adjective-noun order and provide an answer for Research Question 1.3. (Does the language of the carrier phrase determine the order of the adjective-noun?).

In Table 16, we repeat the predictions for Type 4 and Type 3 adjectives under the assumption that the carrier phrase determines adjective-noun word order. Predictions are the same for Type 4 and Type 3 adjectives. The "Spanish Carrier Phrase" column represents the predictions following the ML Hypothesis for conditions with Spanish carrier phrase. In contrast, the "English carrier phrase" column represents the predictions for conditions that contain an English carrier phrase.

Table 16. Predictions arising from the ML Hypothesis, divided by language of the carrier phrase.

\begin{tabular}{|c|c|c|}
\hline Type of Stimuli & Spanish Carrier Phrase & English Carrier Phrase \\
\hline Condition 1 (ASNE) & $\begin{array}{c}x \\
\text { Ayer Óscar trajo un blanco duckling } \\
\text { 'Yesterday Óscar brought a white duckling' }\end{array}$ & $\begin{array}{l}\checkmark \\
\text { This morning Leo designed an alemán rocket } \\
\text { 'This morning Leo designed a German rocket' }\end{array}$ \\
\hline Condition 2 (NEAS) & $\begin{array}{c}\checkmark \\
\text { Ayer Óscar trajo un duckling blanco } \\
\text { 'Yesterday Óscar brought a white duckling' }\end{array}$ & $\begin{array}{c}x \\
\text { This morning Leo designed a rocket alemán } \\
\text { 'This morning Leo designed a German rocket' }\end{array}$ \\
\hline Condition 3 (AENS) & $\begin{array}{c}\boldsymbol{x} \\
\text { Ayer Óscar trajo un white patito } \\
\text { 'Yesterday Óscar brought a white duckling' }\end{array}$ & $\begin{array}{l}\checkmark \\
\text { This morning Leo designed a German cohete } \\
\text { 'This morning Leo designed a German rocket' }\end{array}$ \\
\hline Condition 4 (NSAE) & $\begin{array}{c}\checkmark \\
\text { Ayer Óscar trajo un patito white } \\
\text { 'Yesterday Óscar brought a white duckling' }\end{array}$ & $\begin{array}{l}x \\
\text { This morning Leo designed a cohete German } \\
\text { 'This morning Leo designed a German rocket' }\end{array}$ \\
\hline
\end{tabular}


First, take a look at the conditions with Spanish carrier phrase. Recall that this hypothesis suggests that the noun-adjective order should follow the language of the matrix language/carrier phrase. Thus, for conditions with Spanish carrier phrase, conditions with adjectives in postnominal position should be preferred because in Spanish, the unmarked order is NA. When comparing conditions with Spanish adjectives (Condition 1 and 2), Condition 2 should be preferred over 1. For Conditions with English adjectives, Condition 4 (adjectives in postnominal position) should be preferred over Condition 3 (adjectives in prenominal position).

Now we report the predictions for the conditions that have English as carrier phrase. According to this theory, the adjective-noun order must follow the order of the language of the carrier phrase, thus conditions that contain adjectives in prenominal position must be preferred because in English adjectives appear in prenominal position. Hence, for conditions with Spanish adjectives (Condition 1 and 2), Condition 1 should be preferred over 2. Regarding conditions with English adjectives (Condition 3 and 4), Condition 3 should be preferred over 4 .

The mean overall rating for each condition on the 1-7 Likert scale, SDs, and 95\% Confidence Intervals are illustrated in Table 17, and there is a visual representation in Figure 3 below. This time, we did not distinguish our results by adjective type because according to the carrier phrase hypothesis, the adjective type is not important when predicting the noun-adjective order.

Table 17. Ratings for all adjectives by carrier phrase.

\begin{tabular}{|c|c|c|}
\hline Type of Stimuli & Spanish Carrier Phrase & English Carrier Phrase \\
\hline & $\begin{array}{c}M(S D) \\
{[C I]}\end{array}$ & $\begin{array}{c}M(S D) \\
{[C I]}\end{array}$ \\
\hline Condition 1 (ASNE) & $\begin{array}{c}\text { Ayer Daniel fotografió un español painting } \\
\qquad \begin{array}{c}3.44(2.28) \\
{[3.18,3.71]}\end{array}\end{array}$ & $\begin{array}{l}\text { Yesterday Lucas photographed an español painting } \\
\qquad \begin{array}{c}2.55(2.09) \\
{[2.31,2.79]}\end{array}\end{array}$ \\
\hline Condition 2 (NEAS) & $\begin{array}{c}\text { Ayer Daniel fotografió un painting español } \\
4.88(2.10) \\
{[4.62,5.12]}\end{array}$ & $\begin{array}{c}\text { Yesterday Lucas photographed a painting español } \\
\qquad \begin{array}{c}3.41(2.23) \\
{[3.16,3.67]}\end{array}\end{array}$ \\
\hline Condition 3 (AENS) & $\begin{array}{c}\text { Ayer Daniel fotografió un Spanish cuadro } \\
3.81(2.24) \\
{[3.55,4.06]}\end{array}$ & $\begin{array}{c}\text { Yesterday Lucas photographed a Spanish cuadro } \\
4.05(2.27) \\
{[3.79,4.31]}\end{array}$ \\
\hline Condition 4 (NSAE) & $\begin{array}{c}\text { Ayer Daniel fotografió un cuadro Spanish } \\
4.09(2.24) \\
{[3.83,4.35]}\end{array}$ & $\begin{array}{c}\text { Yesterday Lucas photographed a cuadro Spanish } \\
2.40(2.00) \\
{[2.17,2.63]}\end{array}$ \\
\hline
\end{tabular}

As observed, for conditions with a Spanish carrier phrase, Condition 1 was the lowest rated while Condition 2 was the highest one. On the other hand, for conditions with an English carrier phrase, Condition 4 was the lowest rated and Condition 3 was the most preferred condition.

Another General Linear Mixed Model was run using MIXED procedure in SPSS 24 with rating as the dependent variable and adjective language, adjective position, and language of the carrier phrase as fixed effects. We started the analysis with the maximal structure (see Barr et al. 2013). This included random intercepts at the subject and item levels in order to account for individual variation as well as for any variation in the independent variables (i.e., adjective language, adjective position, and carrier) across items. It also included a random by-subject slope over the fixed effects. The maximal model that converged included random intercepts at the subject levels. It also included a random slope of subject across the fixed effects. 


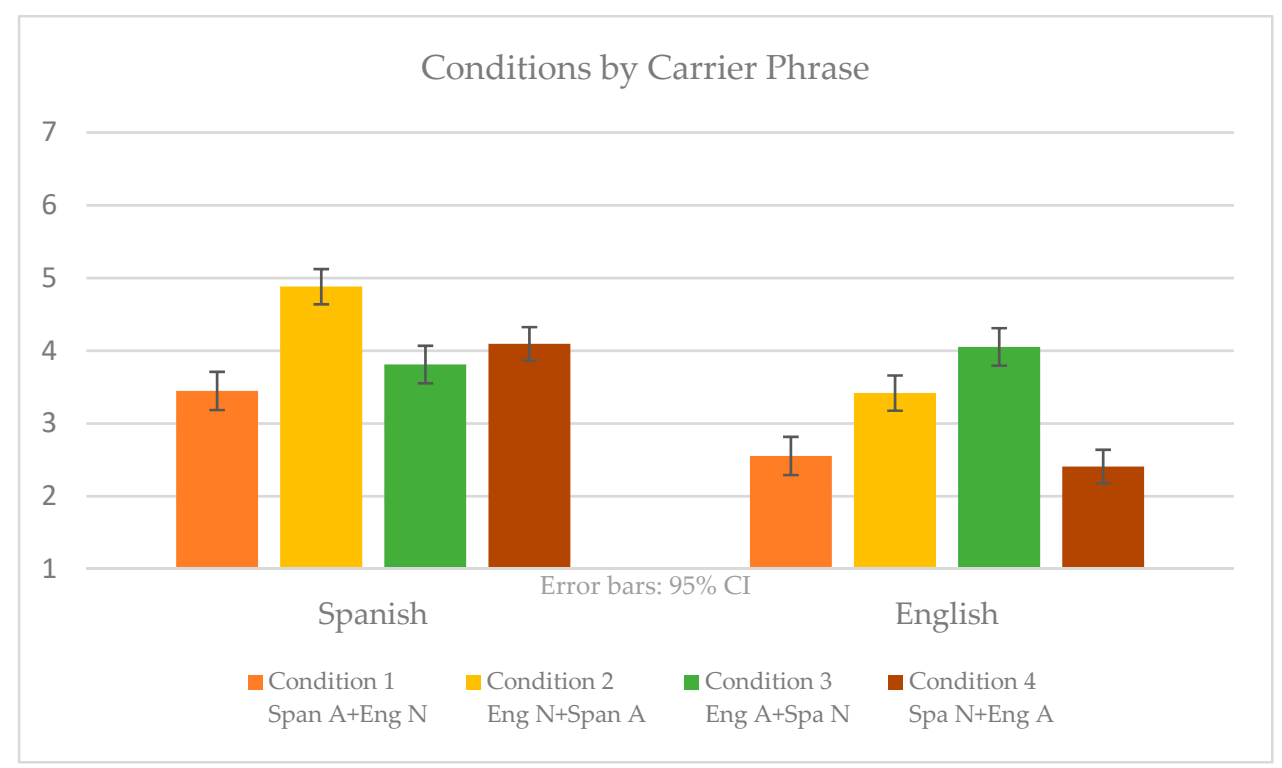

Figure 3. Average scores for adjectives with Spanish and English carrier phrases.

A significant effect was found for Position ${ }^{*}$ Carrier $(F(1,514.825)=29.149, p<0.001)$ and AdjectiveLanguage ${ }^{*}$ Position ${ }^{*}$ Carrier $(\mathrm{F}(3,514.628=12.517, p<0.001)$, which confirms that the language of the carrier phrase can have an effect on participants' ratings. We performed a pairwise contrast which confirmed that participants gave significantly different ratings to different conditions depending on the language of the carrier phrase.

Among the conditions with Spanish carrier phrase, we observe that participants preferred adjectives to appear post-nominally (Condition 2 and 4). As with the previous analysis, we also performed a pairwise contrast and compared conditions that have Spanish adjectives between them (Condition 1 and 2) and conditions with English adjectives between them (Conditions 3 and 4). The pairwise comparison revealed that for conditions with Spanish adjectives, participants preferred Condition $2(p<0.000)$ over Condition 1 with a small effect size $(g=0.63)$, that is participants preferred Spanish adjectives appearing post-nominally. For conditions with English adjectives (Condition 3 and 4), there was a slight preference for Condition 4 over $3(p=0.597)$, although this difference was not significant and the effect size was very small $(g=0.24)$. Thus, participants also showed a slight preference towards English adjectives in post-nominal position (Condition 4) rather than in pre-nominal position (Condition 3).

For conditions with an English carrier phrase, the pairwise comparison revealed that for conditions with Spanish adjectives (Condition 1 and 2), there was a significant preference for Condition 2 (Spanish adjectives in post-nominal position) over $1(p<0.028)$, $(\mathrm{g}=0.40)$. However, according to the ML Hypothesis, the opposite should be expected. For conditions with English adjectives, there was a significant preference for Condition 3 (adjectives in prenominal position) over $4(p<0.000)$, approaching a medium effect size $(\mathrm{g}=0.77)$.

In general, there is a pattern that suggests that the carrier phrase could predict the noun-adjective order. First, when the carrier phrase is Spanish, we found that participants prefer the NA sequence to follow the order of the language of the carrier phrase, regardless of the language of the adjective. That is, we found that participants preferred Spanish and English adjectives to appear in postnominal position (Condition 2 and 4), although the difference between Condition 3 and 4 was not significant.

On the other hand, when the carrier phrase is English, results are different. First, when the adjective is English, we found that participants prefer the NA sequence to follow the order of the language of the carrier phrase and prefer to have English adjectives in pre-nominal position. However, when analyzing Spanish adjectives (Condition 1 and 2), the results did not follow the predictions derived from this hypothesis: participants 
preferred Spanish adjectives in post-nominal position (recall that this is what the Adjective Hypothesis predicts). We provide a discussion of the results in the next section (Section 7).

\section{Discussion}

Our results yield some answers to our research questions. More specifically, our research questions for this experiment asked which of the three elements (the noun, the adjective, or the carrier phrase) established the final order of the constituents within the DP. In order to offer support to one of the hypotheses, acceptability judgment ratings were compared across four different conditions: (1) Spanish adjective + English noun, (2) English noun + Spanish adjective, (3) English adjective + Spanish noun, and (4) Spanish noun + English adjective and two different adjective types: Type 4 adjectives (adjectives that can only appear post-nominally in Spanish: biológico 'biological') and Type 3 adjectives (adjectives that can appear pre-nominally and post-nominally in Spanish, timido 'timid'). It was hypothesized that the adjective was responsible for determining the adjectivenoun order.

First, we analyzed Type 4 adjectives (only postnominal adjectives). The Adjective Hypothesis predicts that for Type 4 adjectives (postnominal adjectives in Spanish), participants would prefer Condition 2 over 1 and Condition 3 over 4 . That is, participants would prefer switches in which the Spanish adjective appears in postnominal position (these adjectives cannot appear pre-nominally in monolingual constructions). For English adjectives, whenever the adjective was English, the predictions were that Condition 3 (the English adjective appearing pre-nominally) should be favored over Condition 4, in which the English adjective appears post-nominally.

Analysis of the ratings suggests that the Adjective Hypothesis could be on the right track, although there are some issues that need further consideration. On the one hand, participants did give higher ratings to Condition 2 (Spanish adjectives in post-nominal position) than to Condition 1 (Spanish adjectives pre-nominally) and this difference was statistically significant. Thus, participants were treating these two conditions in a different way, although effect sizes were small, which indicates that differences are not substantial.

On the other hand, for English adjectives, although Condition 3 (English adjectives pre-nominally) was rated higher than Condition 4 (English adjectives post-nominally), the difference between conditions was not significant. Although we observe a pattern, this presents some difficulties for the Adjective Hypothesis and clearly further research is required.

Second, we also analyzed Type 3 adjectives (adjectives that can appear pre-nominally or post-nominally in Spanish). For these adjectives, according to the Adjective Hypothesis, if the adjective was responsible for determining the order, Condition 2 (adjectives appearing post-nominally) should be preferred over Condition 1, although the difference between these two conditions should be smaller than with Type 4 adjectives. This is because in monolingual constructions, Type 3 adjectives can appear pre-nominally and post-nominally in Spanish and thus, there should be a less clear preference for Condition 2 than with Type 4 adjectives. For English adjectives, once again, Condition 3 should be preferred over Condition 4, that is, constructions with the English adjective appearing in prenominal position.

The results obtained for this experiment with Type 3 adjectives confirmed the Adjective Hypothesis. There was a significant difference between Condition 1 and 2 with a preference for Condition 2 but with a small effect size. Furthermore, the effect size between Condition 1 and 2 was smaller for Type 3 adjectives than with Type 4 ( $g=0.24$ for Type 3 adjectives and $\mathrm{g}=0.68$ for Type 4 adjectives) which goes along with the predictions made by the Adjective Hypothesis. On the other hand, with English adjectives, Condition 3 was statistically preferred over Condition 4, although with a small effect size.

In any case, if the noun were responsible for determining the order of the DP, we should expect the opposite pattern, and Condition 1 should be higher rated than 2 and 4 higher than 3. As these results do not align with the Noun Hypothesis and the pattern found 
is closer to the predictions made by the Adjective Hypothesis, we tentatively conclude that the adjective is responsible for determining the order of the DP.

In addition, the last research question investigated in this experiment looked at the effect of the matrix language. That is, if the carrier phrase is present, does the carrier phrase influence the noun-adjective order? We found a pattern that could indicate that the matrix language (the carrier phrase) is intervening although results are not conclusive, especially with conditions with English carrier phrase.

First of all, the ML Hypothesis predicts that for conditions with Spanish carrier phrase, conditions with Spanish and English adjectives appearing in postnominal position should be preferred and this is what we found. Conditions with Spanish adjectives appearing postnominally (Condition 2) were preferred over conditions with Spanish adjectives appearing pre-nominally (Condition 1). The same was found for English: Condition 4 (English adjectives in postnominal position) was preferred over Condition 3 (English adjectives in prenominal position), although the difference between Condition 3 and Condition 4 was not significant. However, recall that we should not expect this pattern according to the Adjective Hypothesis.

For conditions with an English carrier phrase, conditions with Spanish and English adjectives in prenominal position should be preferred. We found that participants prefer conditions with English adjectives appearing pre-nominally (Condition 3) than post-nominally (Condition 4) and this difference was significant. However, with Spanish adjectives we did not find this pattern. Participants preferred conditions with Spanish adjectives appearing post-nominally (Condition 2 ) than pre-nominally (Condition 1 ) and this difference was significant. The ML Hypothesis does not predict this outcome and instead, the opposite should be expected.

In sum, although we found that some non-significant results do not affirmatively support the Adjective Hypothesis, neither do they support the other two hypotheses; on the other hand, multiple other significant results do support the Adjective Hypothesis while arguing against the other hypotheses. Thus, based on the findings, we contend that the Adjective Hypothesis best explains the results found in this experiment and thus, our results agree with Cantone and MacSwan (2009); Moro Quintanilla (2016); Vanden Wyngaerd (2016) and Stadthagen-González et al. (2017). Nevertheless, we also argue that a combination of both the Adjective and the ML Hypothesis could also explain our results because we found that with conditions with a Spanish carrier phrase, English adjectives were preferred post-nominally and this outcome cannot be explained by the Adjective Hypothesis. Thus, further research is required in order to analyze the effect of the carrier phrase.

In addition, we are aware that the preference for the conditions are not categorical and confidence intervals are small which indicates that ratings show variability for both adjective types. The reason for this could be that the participants selected are not that similar among them, although we treated these heritage speakers as a homogeneous group. However, it is known that the degree of proficiency of the heritage language of the heritage speakers varies significantly and spans a wide spectrum (Montrul 2017). Therefore, our next steps will be to examine the participant pool, and analyze if there is any difference among participants, any indicator that would predict this variability in the experimental conditions. In addition, by isolating these variables, results may lead towards a more categorical answer.

\section{Conclusions and Limitations}

In order to offer further support to one of the hypotheses, the Noun Hypothesis, the Adjective Hypothesis, or the ML Hypothesis, we conducted an English/Spanish codeswitching experiment. In this experiment, we provided a new perspective to the nounadjective ordering problem by dividing adjectives by type and making different predictions taking into account the type of the adjective. This division has been ignored in the literature that has examined this issue. Furthermore, some of the literature that analyzed noun- 
adjective order within the DP used some adjectives that were not restricted to Spanish post-nominal position, and this could have influenced their results (Stadthagen-González et al. 2017; Vanden Wyngaerd 2016).

For this experiment, 30 Spanish/English bilinguals took part. The task consisted of an AJT with English/Spanish switches and included Type 4 (only post-nominal adjectives in Spanish such as biológico 'biological') and Type 3 (pre-nominal and post-nominal Spanish adjectives such as timido 'timid') adjectives. Findings for our experiment indicate that the adjective is responsible for determining the final adjective-noun order because our results best match the predictions derived from the Adjective Hypothesis and thus, agree with Cantone and MacSwan (2009); Moro Quintanilla (2016); Vanden Wyngaerd (2016) and Stadthagen-González et al. (2017). However, we also argue that it can be a combination of both the adjective and the carrier phrase which influences the order of the adjective-noun and thus, further research is required.

Finally, to the extent that our study provides evidence in favor of the role of the adjective in the word order within the DP, it provides evidence for an Agree-based mechanism for displacement, as in Chomsky (2000).

Even though we contend that our results contribute to the discussion on noun-adjective order, we are aware of some limitations that need further consideration. First of all, the results of the experiment provided substantial variability (big SDs) which are indicative of individual variation. Thus, our next step will be to examine the participant pool and analyze if there is any indicator that would predict this variability in the experimental conditions. It seems that among participants with worst attitudes towards code switching and among the most English-proficient participants, average ratings are much lower than with other participants. Thus, it would be interesting to analyze these results taking into account this variability.

Secondly, participants were not interviewed in both languages prior to the experiment. Instead, participants saw instructions in both languages but this may not have been enough to activate both languages and this can have an influence in participants' ratings. For further analysis, another alternative such as interviews in code switching should be considered in order to put participants in a bilingual mode before completing the AJTs (Grosjean 2001).

In addition, apart from controlling for frequency, a debriefing questionnaire to determine which items participants are familiar with should be distributed. This is because the Davies corpus does not necessarily reflect the Spanish that these particular speakers are exposed to.

Author Contributions: Conceptualization, I.D.N. and L.L.; methodology, I.D.N. and L.L.; formal analysis, I.D.N. and L.L.; investigation, I.D.N. and L.L.; writing—original draft preparation, I.D.N.; writing - review and editing, L.L.; supervision, L.L. All authors have read and agreed to the published version of the manuscript.

Funding: This research received no external funding.

Institutional Review Board Statement: The study was conducted in accordance with the Declaration of Helsinki, and approved by the Institutional Review Board (or Ethics Committee) of University of Illinois at Chicago (2009-0121).

Informed Consent Statement: Informed consent was obtained from all subjects involved in the study.

Data Availability Statement: The data presented in this study are available on request from the corresponding author. The data are not publicly available due to privacy restrictions.

Conflicts of Interest: The authors declare no conflict of interest.

\section{Notes}

There are some exceptions. A first type of exception is the NA usage in formulaic phrases (courts martial, attorney general). The second type of exception involves indefinite pronouns that include the constituent 'some': (something good). Since these exceptions are few and well-circumscribed, we ignore them for the purposes of this article. 
2 Thurstone's law takes the results of the 2AFC and places them in a "single interval scale that represents a one dimensional quality" (Stadthagen-González et al. 2018, p. 72). This scale provides granularity unlike other Forced Choice Tasks and it is similar to the data obtained with AJTs but with much higher statistical power (Sprouse and Almeida 2011).

\section{References}

Arnaus Gil, Laia, Nadine Eichler, Jansen Veronika, Marisa Patuto, and Natascha Müller. 2012. The Syntax of Mixed DPs Containing an Adjective: Evidence from Bilingual German-Romance (French, Italian, Spanish) Children. In Selected Proceedings of the 14th Hispanic Linguistics Symposium. Edited by Kimberly Geeslin and Manuel Díaz-Campos. Somerville: Cascadilla Proceedings Project, pp. 242-57.

Badiola, Lucía, Rodrigo Delgado, Ariane Sande, and Sara Stefanich. 2018. Attitudes towards Code-Switching and their effects on Acceptability Judgments Tasks. Linguistics Approaches to Bilingualism (LAB) 8: 5-24. [CrossRef]

Bally, Charles. 1965. Linguistique generale et linguistique française. Berne: Éditions Francke.

Barr, Dale J., Roger Levy, Christoph Scheepers, and Harry J. Tily. 2013. Random effects structure for confirmatory hypothesis testing: Keep it maximal. Journal of Memory and Language 68: 255-78. [CrossRef] [PubMed]

Bartlett, Laura. 2012. Syntactic selection and code-switching. Paper presented at Code-Switching in the Bilingual Child: Within and across the Clause, Bergische Universität, Wuppertal, Germany, April 18-20.

Bartlett, Laura. 2013. Adjectives that Aren't. An ERP-Theoretical Analysis of Adjectives in Spanish. Doctoral dissertation, University of Illinois at Chicago, Chicago, IL, USA. Unpublished.

Birdsong, David, Libby M. Gertken, and Mark Amengual. 2012. Bilingual Language Profile: An Easy-to-Use Instrument to Assess Bilingualism. Austin: University of Texas at Austin.

Boleda, Gemma, and Louise McNally. 2004. Relational adjectives as properties of kinds. In Empirical Issues in Formal Syntax and Semantics. 5. Edited by Olivier Bonami and Patricia Cabredo Hofherr. Paris: 5eme Colloque de Syntaxe et Sémantique à Paris, pp. 179-96.

Bortolotto, Laura. 2016. The Syntax of Relational Adjectives in Romance: A Cartographic Approach. Doctoral dissertation, Università Ca'Foscari, Venezi, Italy.

Bosque, Ignacio. 1993. Sobre las diferencias entre los adjetivos relacionales y los calificativos. Revista Argentina de Lingüística 9: 9-48.

Bosque, Ignacio. 2001. Adjective Position and the Interpretation of Indefinites. In Current Issues in Spanish Syntax and Semantics. Edited by Rexachand J. Gutiérrez and Villar L. Silva. Berlin: Mouton de Gruyter, pp. 17-63.

Brinker, Jacques H. 1974. L'aggettivo di relazione nell'italiano moderno. In Fenomeni morfologici e sintattici nell'italiano contemporaneo. SLI 7/1. Edited by Mario Medici and Antonella Sangregorio. Roma: Bulzoni, pp. 5-19.

Camacho, José. 2018. The Interpretation of Adjective-N Sequences in Spanish Heritage. Languages 3: 46. [CrossRef]

Cantone, Katia F., and Jeff MacSwan. 2009. Adjectives and Word Order: A Focus on Italian-German Code-switching. In Multidisciplinary Approaches to Code-Switching. Edited by Isurin L. Winford and de Donald K. Bot. Amsterdam: John Benjamins, pp. $243-78$.

Chomsky, Noam. 1993. A Minimalist Program for Linguistic Theory. MIT Occasional Papers in Linguistics. Cambridge: The MIT Press, pp. 1-67.

Chomsky, Noam. 2000. Minimalist Inquiries: The Framework. In Step by Step: Essays on Minimalist Syntax in Honor of Howard Lasnik. Edited by Roger Martin, David Michaels and Juan Uriagereka. Cambridge: The MIT Press, pp. 89-155.

Cinque, Guglielmo. 1994. Adverbs and Functional Heads: A Cross-Linguistics Perspective. Oxford, UK: Oxford University Press.

Cinque, Guglielmo. 2005. Deriving Greenberg's Universal 20 and Its Exceptions. Linguistic Inquiry 36: 315-32. [CrossRef]

Cinque, Guglielmo. 2010. The Syntax of Adjectives. Cambridge: The MIT Press.

Cowart, Wayne. 1996. Experimental Syntax: Applying Objective Methods to Sentence Judgments. California: Sage Publications Inc.

Davies, Mark. 2006. A Frequency Dictionary of Spanish. New York and London: Routledge.

De Nicolas, Irati, and Jon Robledo. 2018. Adjective placement in Spanish and Basque mixed DPs. In Code Switching: Experimental Answers for Theoretical Questions. In Honor of Kay González-Vilbazo. Edited by Luis López. New York: John Benjamins, pp. 63-100.

Demonte, Violeta. 1999. El adjetivo: Clases y usos. La posición del adjetivo en el sintagma nominal. In Gramática descriptiva de la lengua española, vol. 1: Sintaxis básica de las clases de palabras. Edited by Ignacio Bosque and Violeta Demonte. Colección Nebrija y Bello and Madrid: Real Academia Española, pp. 129-215.

Di Sciullo, Anna Maria. 2014. On the Asymmetric Nature of the Operations of Grammar: Evidence from Codeswitching. In Grammatical Teory and Bilingual Code-Switching. Edited by Jeff MacSwan. Cambridge: The MIT Press, pp. 63-85.

Fábregas, Antonio. 2007. The internal syntactic structure of relational adjectives. Probus 19: 1-36. [CrossRef]

González-Vilbazo, Kay E., Laura Bartlett, Sarah Downey-Giménez, Shane Ebert, Jeanne Heil, Bradley Hoot, and Sergio E. Ramos. 2013. Methodological considerations in code-switching research. Studies in Hispanic and Lusophone Linguistics 6: 119-38. [CrossRef]

Grosjean, Francois. 2001. The bilingual's language modes. In One Mind, Two Languages: Bilingual Language Processing. Edited by Janet L. Nicol. Oxford: Blackwell, pp. 1-22.

Kayne, Richard S. 1993. The Antisymmetry of Syntax. Cambridge: The MIT Press.

Linck, Jared A., and Ian Cunnings. 2015. The Utility and Application of Mixed-Effects Models in Second Language Research. Language Learning 65: 185-207. [CrossRef]

Longobardi, Giuseppe. 1994. Reference and Proper Names: A Theory of N-Movement in Syntax and Logical Form. Linguistic Inquiry 25: 609-65. 
Marantz, Alec. 1997. No Escape from Syntax: Don't Try Morphological Analysis in the Privacy of Your Own Lexicon. University of Pennsylvania Working Papers in Linguistics: Vol. 4: Iss. 2, Article 14. Available online: https://repository.upenn.edu/pwpl/vol4 /iss2/14 (accessed on 24 January 2022).

Montrul, Silvina. 2017. The bilingual development of Heritage speakers. In The Acquisition of Heritage Languages. Cambridge: Cambridge University Press.

Moro Quintanilla, Mónica. 2016. El Programa Minimalista y los Adjetivos Modificadores del Nombre en la Alternancia Lingüística Español-Inglés [The minimalist Program and Noun-Modifying Adjectives in Spanish-English Codeswitching]. RAEL: Revista Electrónica de Lingüística Aplicada 15: 21-35.

Moyer, Melissa. 1992. Analysis of Code-Switching in Gibraltar. Doctoral dissertation, Universidad Autónoma de Barcelona, Barcelona, Spain. Unpublished.

Myers-Scotton, Carol. 2002. Contact Linguistics: Bilingual Encounters and Grammatical Outcomes. Oxford: Oxford University Press.

Pablos, Leticia, Maria Carmen Parafita Couto, Bastian Boutonnet, Amy De Jong, Marlou Perquin, Annelles de Haan, and Niels O. Schiller. 2018. Adjective-Noun Order in Papiamento-Dutch code-switching. Linguistic Approaches to Bilingualism 9: 710-57. [CrossRef]

Parafita Couto, Maria Carmen, Margaret Deuchar, and Marika Fusser. 2015. How do Welsh-English bilinguals deal with conflict? Adjective-noun order resolution. In Code-Switching Between Structural and Sociolinguistic Perspectives. Edited by Gerald Stell and Kofi Yakpo. Berlin: Mouton de Gruyter, pp. 65-84.

Parafita Couto, Maria Carmen, Bastien Boutonnet, Noriko Hoshino, Peredur Webb-Davies, Margaret Deuchar, and Guillaume Thierry. 2017. Testing alternative theoretical accounts of code-switching using event-related brain potentials: A pilot study on WelshEnglish. In Bilingualism and Minority Languages in Europe: Current Trends and Developments. Edited by Fraser Lauchlan and Mari Carmen Parafita Couto. Newcastle: Cambridge Scholars, pp. 242-56.

Plonsky, Luke, and Frederick L. Oswald. 2014. How big is “big"? Interpreting effect sizes in L2 research. Language Learning 64: 878-912. [CrossRef]

Sande, Ariane. 2018. C plus T as a Necessary Condition for Pro-Drop: Evidence from Code-Switching. Doctoral dissertation, University of Illinois at Chicago, Chicago, IL, USA. Unpublished.

Schütze, Carson T., and Jon Sprouse. 2013. Judgment data. In Research Methods in Linguistics. Edited by Robert J. Podesva and Devyani Sharma. New York: Cambridge University Press, pp. 27-50.

Slabakova, Roumyana, Jennifer Cabrelli Amaro, and Sang Kyung Kang. 2016. Regular and novel metonymy: Can you curl up with a good Agatha Christie in your second language? Applied Linguistics 37: 175-97. [CrossRef]

Sprouse, Jon, and Diogo Almeida. 2011. Power in Acceptability Judgment Experiments and the Reliability of Data in Syntax. Master's thesis, 2011, University of California, Irvine, CA, USA, Michigan State University, East Lansing, MI, USA.

Stadthagen-González, Hans, Maria Carmen Parafita Couto, C. Alejandro Párraga, and Markus F. Damian. 2017. Testing Alternative Theoretical accounts of code-switching: Insights from Three Corporative Judgments of Adjective Noun Order. International Journal of Bilingualism 23: 200-20. [CrossRef]

Stadthagen-González, Hans, Luis López, Maria Carmen Parafita Couto, and Alejandro Párraga. 2018. Using two-alternative forced choice tasks and Thurstone's law of comparative judgments for code-switching research. Linguistic Approaches to Bilingualism 8: 67-97. [CrossRef]

Stefanich, Sara. 2019. A Morphophonological Account of Spanish/English Word-Internal Codeswitching. Doctoral dissertation, University of Illinois at Chicago, Chicago, IL, USA. Unpublished.

Stefanich, Sara, and Jennifer Cabrelli-Amaro. 2018. Phonological factors of English/Spanish word internal code-switching. In Code-Switching-Experimental Answers to Theoretical Questions, In Honor of Kay González-Vilbazo. Edited by Luis López. New York: John Benjamins, pp. 195-222.

Taboada, Inmaculada. 2010. The Internal Structure of the Non-Quantified DP. Doctoral dissertation, University of the Basque Country, Leioa, Spain. Unpublished.

Vanden Wyngaerd, Emma. 2016. The adjective in Dutch-French code switching: Word order and Agreement. International Journal of Bilingualism 21: 454-73. [CrossRef] 